\title{
Seismic vulnerability curves development for residential buildings using a new qualitative- quantitative damage index based on field observations of Sarpol-e Zahab (Iran) earthquake (MW 7.3)
}

Mohammad Khanmohammadi ( $\Delta$ mkhan@ut.ac.ir)

University of Tehran

\section{Majid Eshraghi}

University of Tehran College of Engineering

\section{Sina Sayadi}

University of Tehran College of Engineering

Milad Ghafarian Mashhadinezhad

University of Tehran College of Engineering

Hamid Zafarani

International Institute of Earthquake Engineering and Seismology

\section{Research Article}

Keywords: Sarpol-e Zahab earthquake. Earthquake damaged buildings, Damage classification. Damage index. Empirical vulnerability curve

Posted Date: February 9th, 2022

DOI: https://doi.org/10.21203/rs.3.rs-1332207/v1

License: (c) (i) This work is licensed under a Creative Commons Attribution 4.0 International License.

Read Full License 


\title{
Seismic vulnerability curves development for residential buildings using a new qualitative- quantitative damage index based on field observations of Sarpol-e Zahab (Iran) earthquake (Mw 7.3)
}

\author{
*Mohammad Khanmohammadi' ${ }^{1}$ Majid Eshraghi' ${ }^{1}$ Sina Sayadi'. Milad Ghafarian \\ Mashhadinezhad ${ }^{1}$. Hamid Zafarani² \\ ${ }^{1}$ School of Civil Engineering, College of Engineering, University of Tehran, Tehran, Iran \\ ${ }^{2}$ International Institute of Earthquake Engineering and Seismology, Tehran, Iran \\ *Corresponding Author E-mail address: mkhan@ut.ac.ir (M. Khanmohammadi)
}

\begin{abstract}
Following a severe disaster, a quick and reliable evaluation of the structural damage state is one of the crucial steps to making decisions and disaster management. Based on a realistic estimate of types and levels of damages, decisions related to the structural performances, repair possibility, or in severe cases, a replacement could be made. In available technical literature, reporting the classification of damaged buildings is limited and based on numerical studies, laboratory tests, and inspector's judgment. Presented results in current research are from a comprehensive and meticulous investigation of more than 81 damaged steel and RC buildings after the Sarpol-e Zahab (Iran) earthquake. Considering this valuable collected information, a novel qualitative-quantitative approach is introduced to classify damaged steel and RC buildings into 5 damage states, both for structural and non-structural components. For this purpose, weights are attributed to each type of damage, according to the severity of the damage observed in each component and its influence on the damage to the entire building. Then, the damage index of each structure is obtained using the proposed relation, and results are compared with field observation for verification. Finally, empirical vulnerability curves of investigated buildings are developed based on the proposed damage index and spectral acceleration at fundamental periods of structures as an intensity measure.
\end{abstract}

\section{Keywords (4 to 6 words)}

Sarpol-e Zahab earthquake. Earthquake damaged buildings, Damage classification. Damage index. Empirical vulnerability curve. 


\section{Introduction}

One of the essential steps for structural safety assessment after a catastrophic earthquake is analyzing the severity, extent, and type of damages that occurred to the structure. The results of this analysis lead to designating a building as safe and able to remain occupied, requiring minor repairs of non-structural elements, required to be retrofitted in some structural elements, and finally, economically or technically unrepairable. Therefore, whatever the initial assessment of a building is more accurate, the probability of making mistakes reduces. Furthermore, in the case of retrofitting, the evaluator would have a more realistic view of the building's inherent weaknesses, damage due to an earthquake, and residual capacity of structural elements. For this aim, many analytical, experimental, and field research have been conducted to classify buildings in terms of their damage levels. These attempts lead to the definition of different damage states (DSs). Moreover, attempts have been made to quantify damage state (DS) classifications that eventually lead to the definition of damage indices. In fact, DS and damage index (DI) are appropriate and relatively exact tools for leveling the extent and severity of damage taken place in buildings, and consequently for deciding the capability of structural retrofitting and estimating the approximate cost of this process. Grünthal (1998) classified reinforced concrete (RC) and masonry buildings into 5 DSs based on field observations of happened earthquakes in the world. Brzev et al. (2017) stated that in most existing studies, such as Grünthal (1998), column damage is often attributed to the flexural failure mechanism. Considering the study of $98 \mathrm{RC}$ buildings damaged by the 2015 Gorkha earthquake, Nepal, this research proposed a modification to RC buildings' damage classification levels suggested in Grünthal (1998), focusing on the shear failure mechanism. HAZUS (1999) defined 4 DSs for timber, masonry, steel, and RC buildings with different lateral load resisting systems. Also, this instruction proposed the maximum drift ratios of buildings in different DSs. Baggio et al. (2007) proposed 3 DSs for RC and masonry buildings by combining the defined DSs in Grünthal (1998). Anagnostopoulos et al. (2004) classified structural elements, then determined the severity and extent of damage in each class, and finally, based on the severity and extent of damage, classified buildings into 3 DSs. FEMA P-58-1 (2018), by presenting approximate limits proposed by FEMA356 (2000), classified buildings into 4 DSs and suggested a relationship between each story's DSs and residual drift ratio. Dai et al. (2017) examined a large-scale four-story moment frame RC building on a shaking table and suggested 3 DSs and their corresponding residual and maximum drift. Ghobarah (2004) classified different RC buildings into 5 DSs using analytical and experimental data and showed a correlation between DSs and maximum interstory drift.

Rossetto and Elnashai (2003) classified 4 different types of RC buildings into 7 DSs using experimental data. Furthermore, they found a correlation between the defined DSs and a DI, which had a logarithmic relationship with the building's maximum interstory drift. Okada and Takai (2000) proposed a numerical scale to classify damaged buildings based on the defined DSs in Grünthal (1998) and photos of damaged buildings after the 1985 Mexico earthquake. Also, they surveyed a relationship between the defined DI and the suggested DSs in other studies. Sozen (1981) introduced a DI as a function of interstory drift using experimental tests on small-scale structures. His study showed that only some non-structural elements might sustain damages in buildings with interstory drift ratios less than $1 \%$, while it is more likely that interstory drift ratios greater than $4 \%$ cause severe damages to the structural elements to the extent that the building becomes unrepairable or lead to the collapse of the building. Park and Ang 
(1985) proposed a local DI based on a local RC element's ductility and dissipated energy during an earthquake. Moreover, they suggested an approach for calculating the global DI by applying weighting factors on local damage indices. DiPasquale and Cakmak (1988) used changes in the fundamental period of a structure as a measure for structural stiffness variations caused by earthquakes, and Ghobarah et al. (1999) proposed structural (or story) stiffness variations as a DI of a building (or story) using numerical analysis.

The majority of research, reports, and instructions consider the whole building drift or maximum interstory drift ratio as a representative of building DS (e.g., HAZUS 1999, Rossetto and Elnashai 2003, Behboodi et al. 2021). However, this parameter cannot be a realistic representative for building DS evaluation (Otani and Sozen 1972; Sozen 1997). It is also impossible to measure the building's maximum experienced drift in the investigation process after an earthquake. When a structure deforms linearly in height, the drift ratio of the building can be a good indicator of the extent of damage that occurred to the building (Ghobarah 2004). In cases that a structural response is affected by higher vibration modes or there is a soft or weak story in a building, the drift ratio may be declined, which contradicts the steady increase in building drift ratio as damage increases (Rossetto 2004; Ghobarah 2004). On the other hand, although interstory drift can consider some drawbacks of building drift ratios, such as not considering the soft and weak story and higher vibration mode effects, this indicator cannot solely represent damage extent and severity. Conducting experimental tests on RC frames, Otani and Sozen (1972) observed that if an earthquake-damaged RC structure were subjected to another earthquake with the same intensity for the second time, although the structural stiffness at the beginning of the second test is considerably less than the initial state, the achieved maximum drift would be equal to the first test. Therefore, it can be concluded that the maximum (which is not possible to measure after the earthquake) or residual drift cannot solely be the best criterion for the determination of structural DS. Furthermore, as Brzev et al. (2017) mentioned, most of the existing studies and reports only have considered flexural behavior for RC structural elements (which is a ductile behavior and can result in significant drift ratios), while deficiencies in the design and construction process can lead to the development of other failure mechanisms namely, shear mechanism, loss of bond, and other fragile and brittle failures.

To partially address these deficiencies, the present research uses the results of field observations, meticulously collected information of 81 damaged buildings (59 steel and $22 \mathrm{RC}$ buildings) after the Sarpol-e Zahab earthquake, as well as visual inspection of more than 200 damaged buildings in this earthquake to propose a novel and relatively accurate DS classification for typical residential steel and RC buildings. Moreover, concerning the type and importance of damaged elements (column, beam, and brace) and severity and type of the taken place damage, weighting coefficients are assigned to each damaged element. Through this process, an innovative DI is proposed to quantify a building damage intensity. In this regard, a brief overview will be given of the earthquake, building types, and construction practices in that region. After that, various types of damages observed in buildings along with some statistical details are explained. Finally, the weighting coefficient for each damage that happened to each element is assigned according to the damage severity and contribution of the damaged element to the whole structure. The same process is also done for non-structural components and a DI is also defined for the non-structural members of a damaged building. Details and methodology will be explained in detail in section 5. In section 6, a DS evaluation is defined, and in section 7 the proposed methods would be compared and validated against other research and studies. 
Buildings vulnerability assessment using fragility or vulnerability curves is another vital subject in surveying the postearthquake damage data (Rossetto et al. 2014; Martins and Silva 2020; Khanmohammadi and Mazlaghani 2021). The difference between the fragility curve and vulnerability curve is that the former expresses the probability of exceeding a given DS as a function of a seismic intensity measure (IM) (e.g., peak ground acceleration (PGA)), and the latter depicts the loss of a typical building as a function of IM. Vulnerability curves can be developed either directly from data about the amount of damage to buildings or indirectly by merging fragility curves and damage-to-loss consequence models (Rossetto et al. 2014). Although several analytical fragility and vulnerability functions have been developed (e.g., D'ayala et al. 2014; Yepes-Estrada et al. 2016), due to the lack of field data, especially in developing countries, empirical fragility and vulnerability models are less developed.

In Iran, for the first time, Tavakoli and Favakoli (1993) developed the vulnerability of residential buildings based on empirical data from the Manjil earthquake, and the latest results are published according to the information from the Sarpol-e-Zahab earthquake (Biglari and Formisano 2020; Biglari et al. 2021). Meanwhile, some researchers have tried to develop fragility and vulnerability curves for different types of buildings in Iran by collecting a comprehensive database of damages that occurred to buildings in recent earthquakes in Iran (Omidvar et al. 2012; Sadeghi et al. 2015; Tafti et al. 2020). Vulnerability curves have weaknesses, including uncertainty in determining seismic intensity measure (Ioannou et al. 2020). Generally, in Iran, seismic intensity measure is determined based on macro intensity, making it difficult to combine with modern probabilistic seismic hazard models (PSHA). PGA has been used as a seismic intensity measure in recently conducted research. Since most of the recorded damaged buildings in Iran are in a limited range of PGA, the validity of these curves is hence limited. One of the few developed vulnerability curves in Iran with the spectral acceleration parameter is calculated analytically by Kohrangi et al. (2021) for 27 new code conforming building taxonomies. However, no vulnerability curve has been developed based on the results of postearthquake observed field damages so far.

In this research, with regard to the limited number of damaged buildings and also appropriate accuracy in estimating the amount and severity of occurred damages to the buildings, using the proposed damage indices described in section 5 , and the calculated spectral acceleration corresponding to the empirical period of each building, vulnerability curves of 3 types of buildings are developed directly without producing fragility curves. The used approach in this process is described in section 8 .

\section{The catastrophic earthquake of Sarpol-e Zahab}

At 21:48 local time on November 12, 2017, an earthquake with a magnitude of $7.3(\mathrm{Mw})$ and focal depth of about 18 $\mathrm{km}$ struck a region at a distance of $37 \mathrm{~km}$ northwest of Sarpol-e Zahab city located at $45^{\circ} 52$ 'east longitude, and 34 ${ }^{\circ} 24^{\circ}$ latitude in Iran. Historically, two earthquakes of 958 and 1150 AD with an estimated magnitude of 6.4 and 5.9 were reported near that region, which shows a history of high seismicity in this city. All of the structures in this city were renewed 25 years ago following the destructive Iran-Iraq war (1980-1988), and based on our survey, most of the buildings are less than 10 years old. Structurally, most of the rural areas' buildings were masonry, while in the city, there were all types of buildings (steel, RC, and masonry). Buildings were classified into 4 classes after the earthquake 
by investigating evaluation groups: destroyed or unrepairable buildings, buildings that require retrofitting, buildings that require minor non-structural repairs, and intact buildings.

According to the official statistics released from national disaster management, in Sarpol-e Zahab city, approximately 1100 buildings were destroyed, 5000 buildings required minor repairs, and 277 buildings required the retrofitting process. Investigation of destructions in Sarpol-e Zahab city showed that the destructions were not distributed uniformly. Although the building construction practice of different areas was similar, there was a significant difference in destruction distribution in the city. Two utterly different damage trends were observed in the city so that in the northern areas of the main street of the city, which are located at the foot of the mountain, the damage was negligible. The main areas with severe damage were focused on the southern part of the main street, which was near the river and located in fine soft soil (Fig.1). Thus, site conditions played a vital role in damages intensification in Sarpol-e Zahab city. Shear wave velocity in soil was acquired by drilling $30 \mathrm{~m}$ holes in different city areas and conducting field tests. Figure 2 shows the spectrum of shear wave velocity ranges in soil. Comparing Figures 1 and 2 implies a pronounced effect of site conditions on damage extent and buildings destructions.

Careful attention to the recorded time histories in Sarpol-e Zahab reveals considerable differences between northsouth and east-west directions. According to recorded time histories, the PGA of east-west, north-south, and vertical directions are approximately $0.57 \mathrm{~g}, 0.69 \mathrm{~g}$, and $0.33 \mathrm{~g}$, respectively. In addition, the PGV of east-west, north-south, and vertical directions are approximately $52.8 \mathrm{~cm} / \mathrm{s}, 45.5 \mathrm{~cm} / \mathrm{s}$, and $28.3 \mathrm{~cm} / \mathrm{s}$, respectively. In Figure 3 , the earthquake's acceleration, velocity, and displacement records are presented.

Figure 4 compares the acceleration, velocity, and displacement spectrums of the Sarpol-e Zahab earthquake and the corresponding spectrums of the $4^{\text {th }}$ edition of Iranian Code of Practice for Seismic Resistant Design of Buildings (BHRC 2015). As it is evident, in periods less than $0.5 \mathrm{~s}$, the earthquake spectrum shows greater values than the design spectrum in both east-west and north-south directions (dominant periods of the earthquake in east-west, north-south, and vertical directions are approximately $0.3 \mathrm{~s}, 0.22 \mathrm{~s}$, and $0.08 \mathrm{~s}$, respectively). Moreover, the earthquake spectrum has local peaks near 1.1s in both directions, especially in the north-south direction. Concerning the fact that most of the steel and RC buildings had up to 5 stories and their fundamental periods ranged from 1-1.2s, it can be concluded that the synchronization between the buildings' fundamental periods and the spectrum peak near 1.1s plays a significant part in the intensification of such structures destruction.
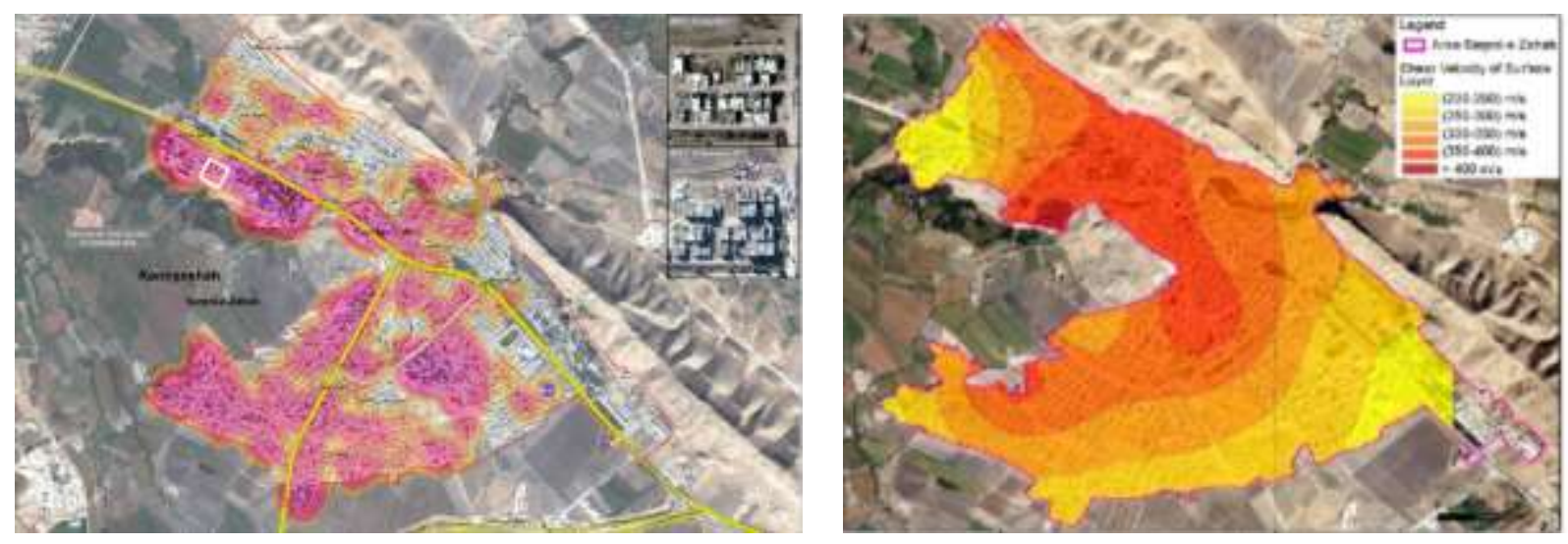

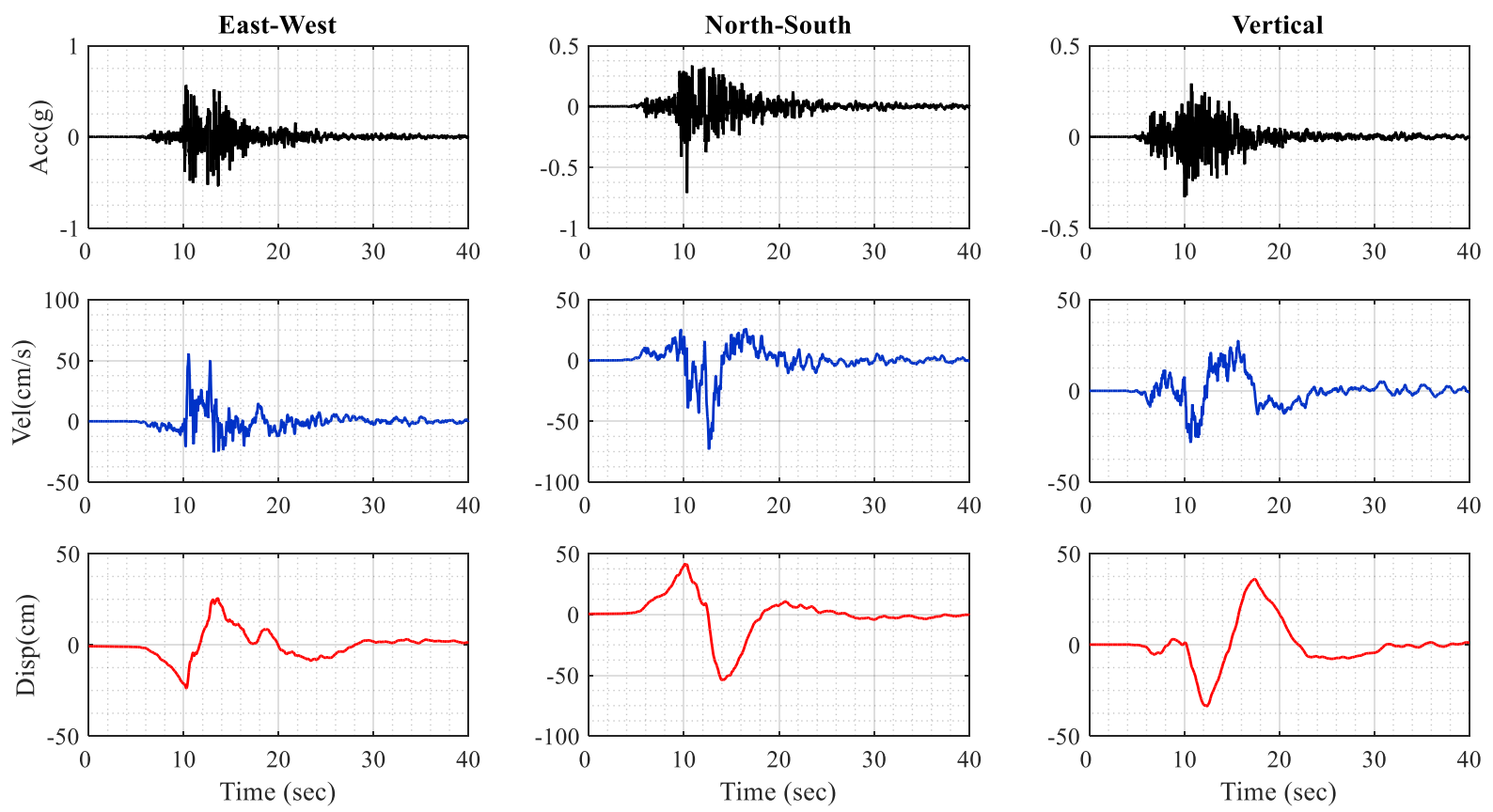

Fig.3. Time histories of the earthquake in Sarpol-e Zahab city in different directions
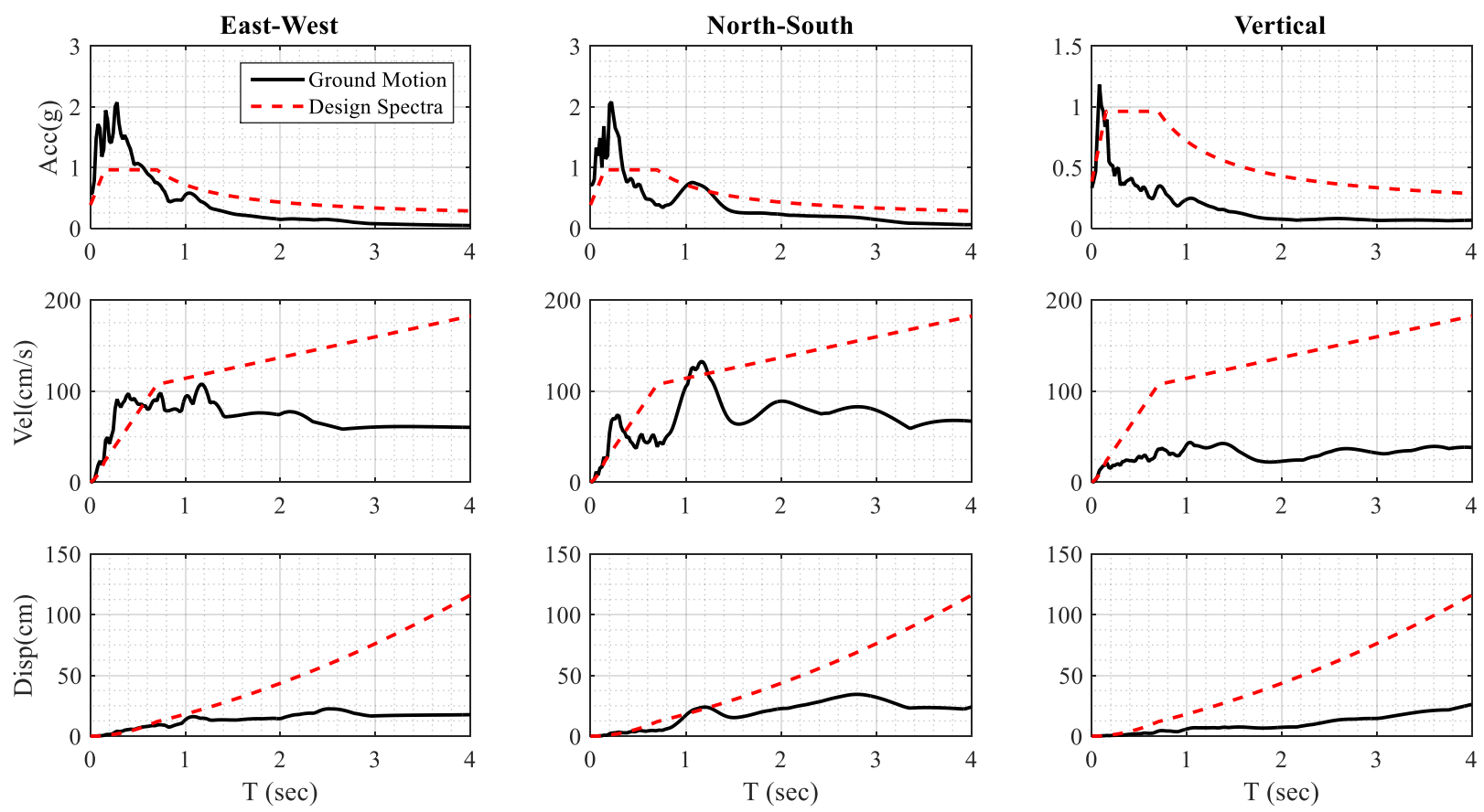

Fig.4. Comparison between acceleration, velocity, and displacement spectrums of Sarpol-e Zahab earthquake and BHRC (2015) spectrum 


\section{Structural damages}

The height of buildings in Sarpol-e Zahab city ranges from 3.5 to 22.3 meters (i.e., 1 to 7 stories). The height distribution of considered buildings is presented in Figure 5. Therefore, the surveyed buildings have 1 to 5 stories in which 3-story buildings are the most frequent buildings. All of the surveyed steel and RC buildings were constructed in the past 10 years and according to the existing design codes and instructions. However, apparent deficiencies in the design and construction process made them prone to severe damages during the earthquake. In the following, explanations and photos are presented with respect to buildings' construction practices and the observed damages after the earthquake.
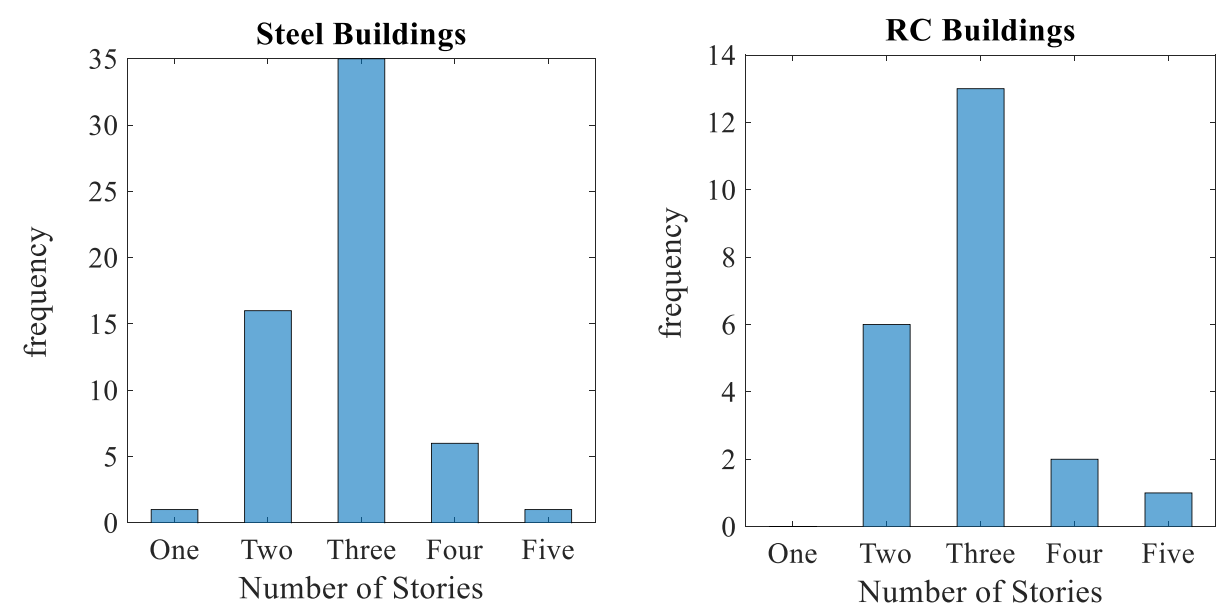

Fig.5. Height histogram of investigated buildings

3.1. Steel buildings

3.1.1. Construction practice of steel buildings

The lateral load resisting systems of most Sarpol-e Zahab steel buildings in longitudinal and transverse directions were concentric bracing (X-bracing) and moment-resisting frame (MRF), respectively. However, a few buildings were exceptional and their lateral load resisting system was eccentric bracing with deficiencies in details and construction. Columns of steel buildings (and generally many cities of Iran) were built-up members composed of two IPE profiles interconnected by batten plates (or strengthening plates) or three IPE profiles that were welded together (it should be noted that these types of columns are acceptable according to Iran's National Building Code Part 10 (ONBR 2013a) for ordinary and intermediate moment-resisting frames, provided that the requirements of compactness and seismic compactness be met, respectively). In the braced direction, beams were IPE profiles, while in the MRFs direction, they were built-up members composed of two IPE profiles that were welded together. Braces were often single IPE or channel; however, some buildings used built-up members composed of two channels or angles.

The main deficiencies of steel buildings stemmed from beam-column connections' behavior. In the direction of MRFs, beams were connected to columns (batten columns) using top plate-bottom plate connection having partial-jointpenetration (PJP) groove or fillet welded flange plates. Due to the absence of a predefined load transfer system from beam to column in the panel zone, connections cannot be considered rigid. Also, construction deficiencies were evident in bracing connections. Braces were connected to the columns' webs using gusset plates, and in most cases, gusset plates were not connected to the soffit flanges of beams.

Samples of steel building construction practices are shown in Figure 6. 

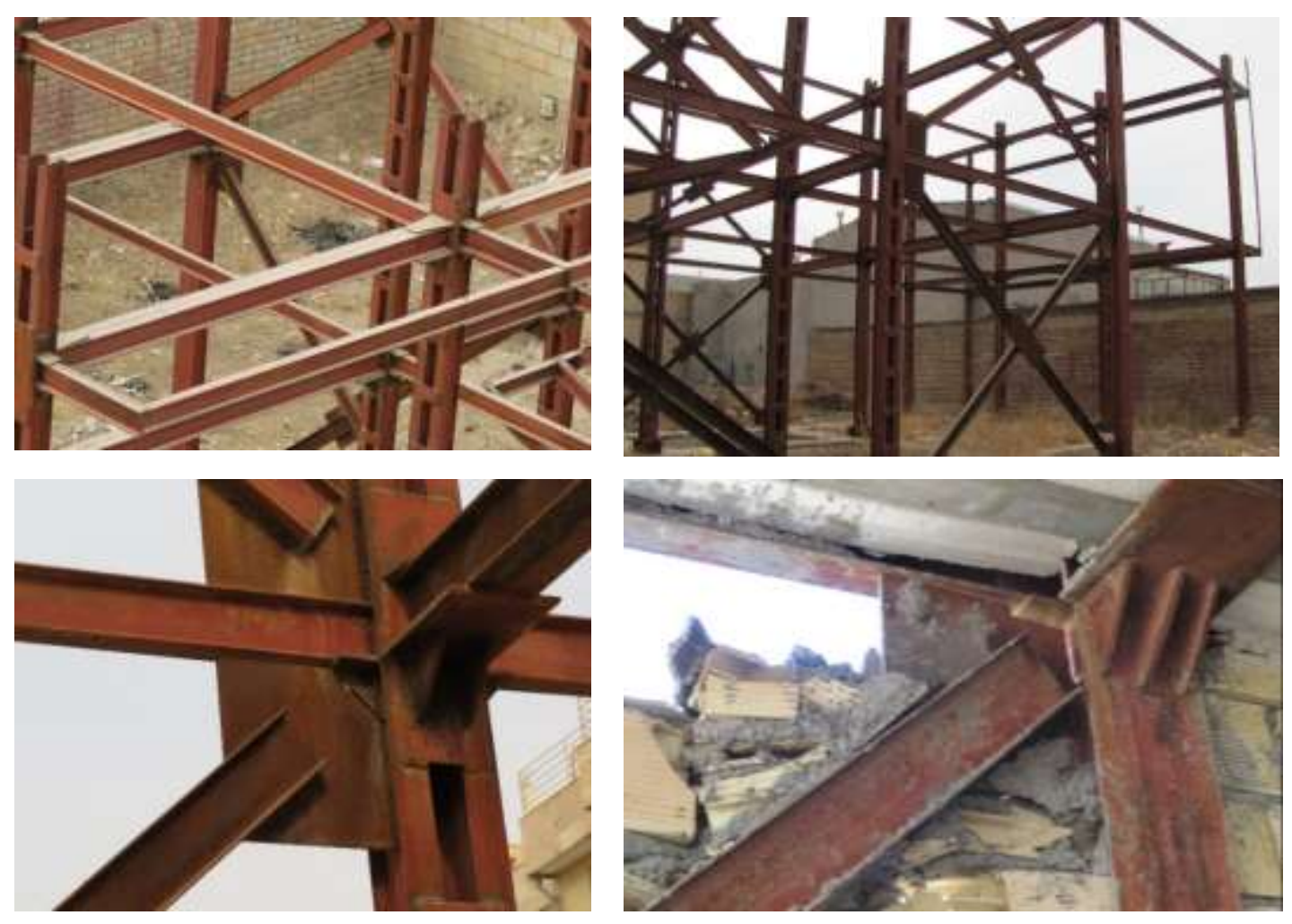

Fig.6. Construction practice of steel buildings in Sarpol-e Zahab city

\subsubsection{Damages}

In steel buildings, the formation of the soft and weak story in the first story of buildings was the origin of damages and destruction of buildings. The soft story's formation can be attributed to lesser stiffness, the taller height of the first story, and removed partition (infill) walls due to the architectural requirements. Weak columns and lack of adequate designed strength in the first story caused many steel buildings to experience weak story behavior. Furthermore, the role of noncompliance with the weak beam-strong column requirements (which, according to Iran's National Building Code Part 10 (ONBR 2013a) is not necessary for ordinary and intermediate moment-resisting frames) is not negligible. Thus, instead of developing the beam-sway mechanism in the MRF direction, the column-sway mechanism was developed and led to high drift ratios and the formation of severe plastic hinges in first story columns (Bruneau et al. 2011) and consequently resulted in the collapse of some buildings. In the braced direction, the soft and weak story formed in the first story due to lack of enough axial strength of brace members (very slender and tension-only designed), inadequate proportioning of brace-connection-beam-column, and improper detailing. These deficiencies were observed in most steel buildings. Although severe damages happened to the first story, other stories remained intact or suffered minor damages (Fig.7). 

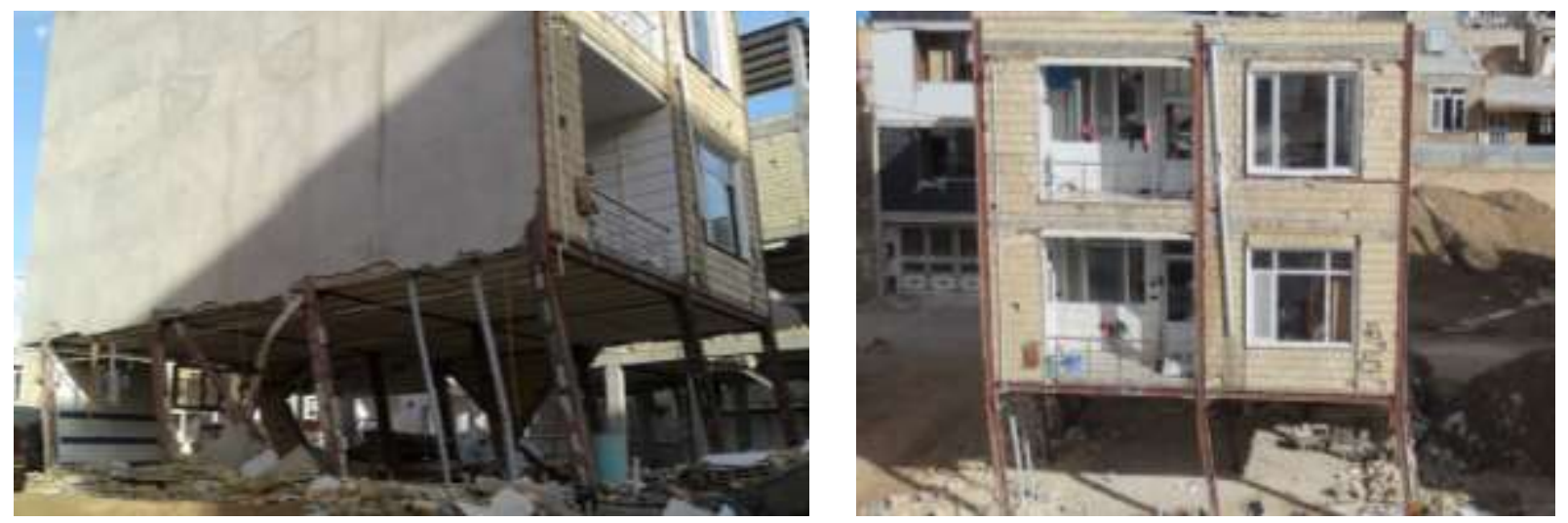

Fig.7. Formation of soft and weak story in the first story of a steel building

In this regard, the first story's lateral stiffness ratio to the second story of the considered steel buildings in both MRF and braced directions is obtained and results are shown in Figure 8. The lateral stiffness in both MRF and bracing direction is computed analytically. Assuming that beams are rigid, a single frame's lateral stiffness in MRF direction is calculated through Equation 1. In the braced direction, assuming that only the bracing elements contribute to the lateral resisting, the stiffness could be calculated through Equation 2.

$$
\begin{aligned}
& K=\sum_{i=1}^{n} \frac{12 E I}{h^{3}} \\
& K=\frac{E A}{L} \cos ^{2}(\theta)
\end{aligned}
$$

where $E, I, A, L, h$, and $\theta$ are young modules, column section moment of inertia, bracing section area, bracing length, and angle between brace element and horizontal axis, respectively. Stiffness is estimated for the first and second stories in each direction. Since height and frame sections remain identical for other stories in almost all buildings, only the first to second story's ratio is presented.

As shown in Figure 8, in the MRF direction of more than 75\% of steel buildings, the first to the second story's stiffness ratio is less than 0.7. According to the $4^{\text {th }}$ edition of Iranian Code of Practice for Seismic Resistant Design of Buildings (BHRC 2015), if the lateral stiffness of each story is less than $70 \%$ and $60 \%$ of this parameter in the upper story, this story would be soft and extreme soft-story, respectively. Concerning this definition, it can be concluded that the first stories of more than $75 \%$ of steel buildings in MRF direction are included in the extreme soft-story or soft-story. Figure 8 indicates that only in one building, this ratio is approximately 1.5. Field observations demonstrate that this one is the only building out of 59 surveyed steel buildings that did not experience any structural damage, and only hairline cracks were observed in some of its partition walls. In the braced direction, although this ratio is less than 1 for approximately $90 \%$ of buildings, the condition is much better than MRF direction, and only $10 \%$ of buildings' first stories are included in soft or extreme soft-story. 

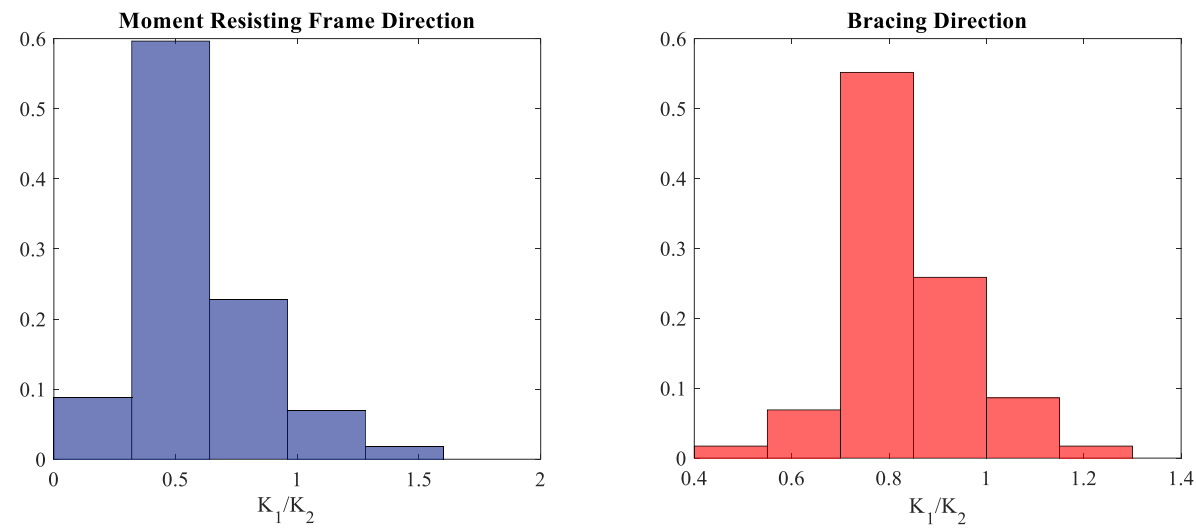

Fig.8. First to second story stiffness ratio histogram for steel buildings

In order to scrutiny steel buildings, the classification of commonly observed damages in each direction is presented. In MRF direction, prevalent damages were as follows: formation of plastic hinges at ends of columns, localized plasticity and deformation in columns' height (skewed column), and global buckling of columns. It is noteworthy that there were no signs of damage to the beams of buildings' moment-frames surveyed in this study. This observation can be attributed to inappropriate behavior of beam-column connections and noncompliance with the weak beam-strong column principle. Based on the severity of the damage, the columns' plastic hinges are classified into 3 levels, i.e., slight, moderate, and severe (Fig.9). There are signs of steel discoloration in a slight plastic hinge in the form of oblique and parallel patterns (Fig.9a). The steel discoloration is prominent in moderate plastic hinges (Fig.9b). Finally, in a severe plastic hinge, wrinkles are visible on the surface of the steel, and by meticulously focusing on this region, the local buckling of column flange (or web) is observable (Fig.9c). Two reasons cause localized plasticity and deformation (skewness) in the height of columns: firstly, due to the concentrated shear force developed at the top end of a column that is connected to a gusset plate, and secondly, owing to the existence of adjacent infill walls which were partially fallen (Fig.10). Local buckling of columns often was occurred at the ends of the column, which is expectable in batten columns (Fig.11). Also, the global buckling of columns was caused by increasing the axial force and high column slenderness.

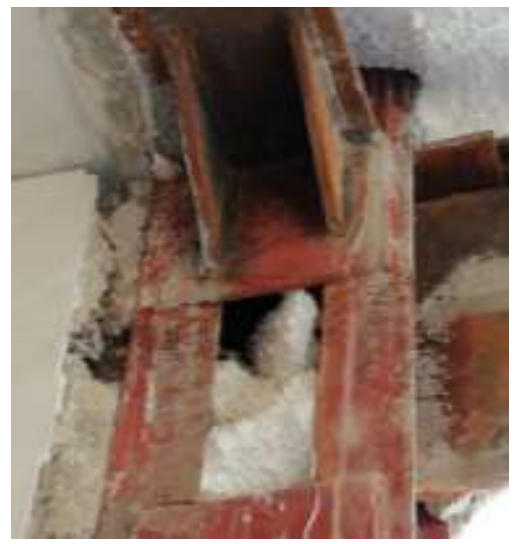

a. Slight plastic hinge at the end of a column Fig.9. Different classes of plastic hinges occur

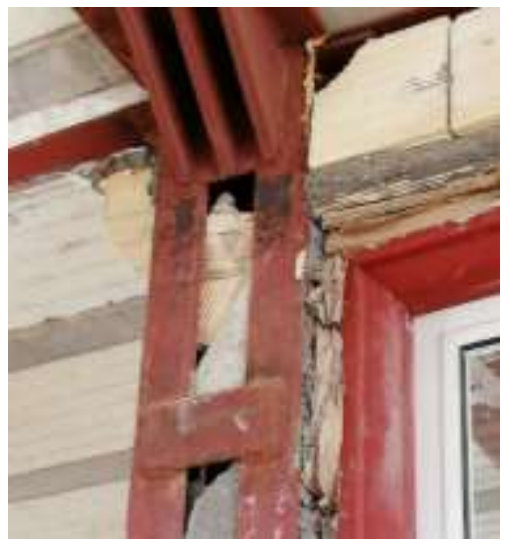

b. Moderate plastic hinge at the end of a column rred at ends of columns

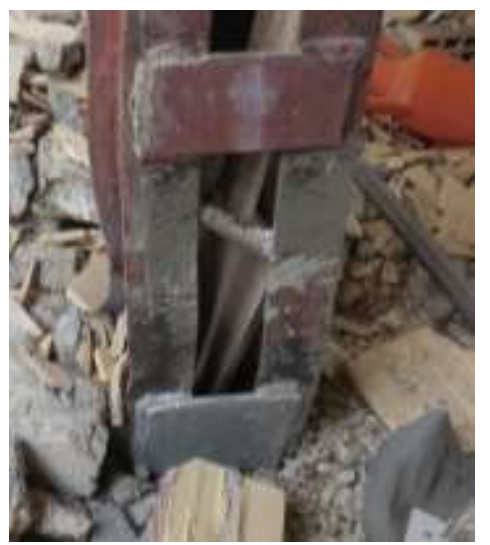

c. Severe plastic hinge at the end of a column 


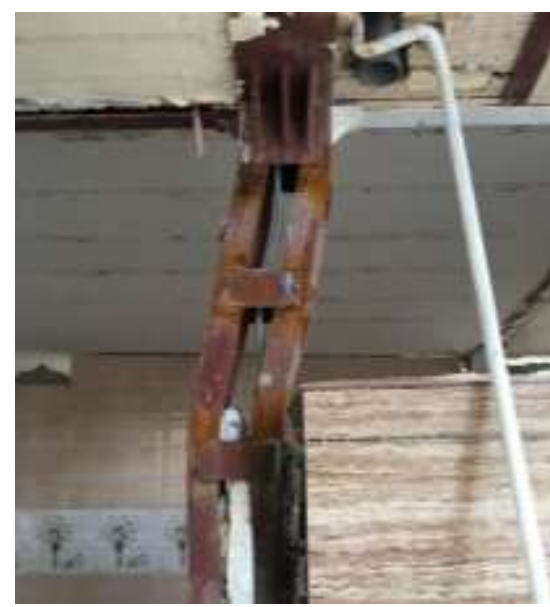

a. Localized plasticity and deformation of a column due to partially falling of an adjacent wall Fig.10. Localized plasticity and deformation of columns (skewed columns)

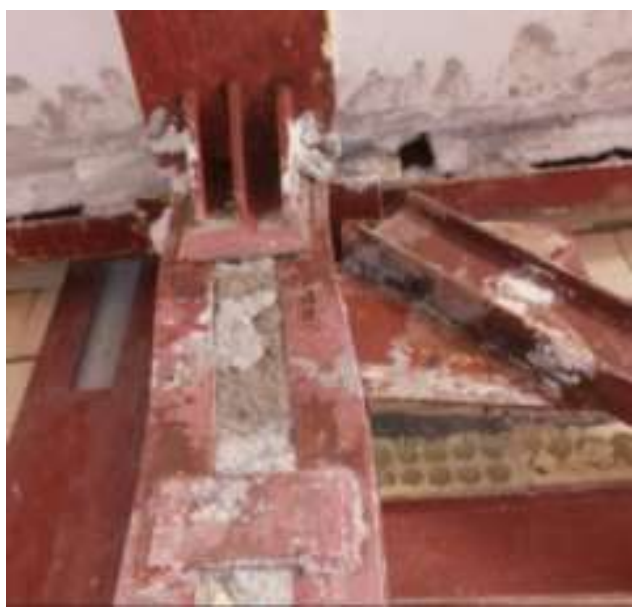

b. Localized plasticity and deformation of a column caused by developed force in brace and transferred to the column

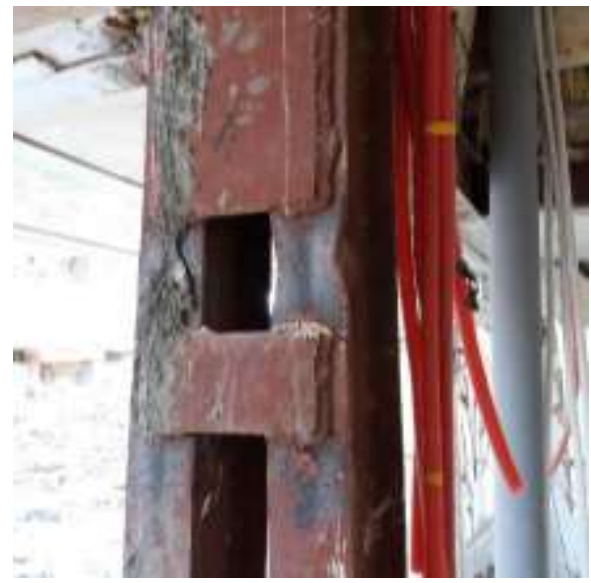

a. Local buckling of column profiles at top of a column between batten plates

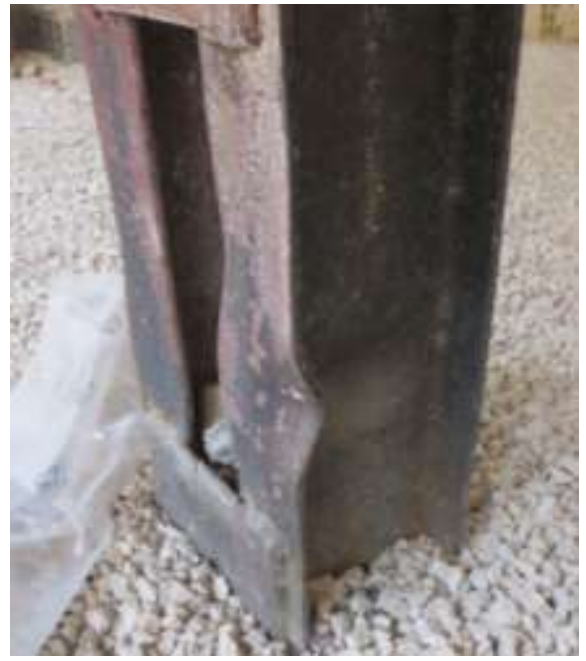

c. Local buckling at severe plastic hinge region at en of a column

Fig.11. Local buckling in steel columns

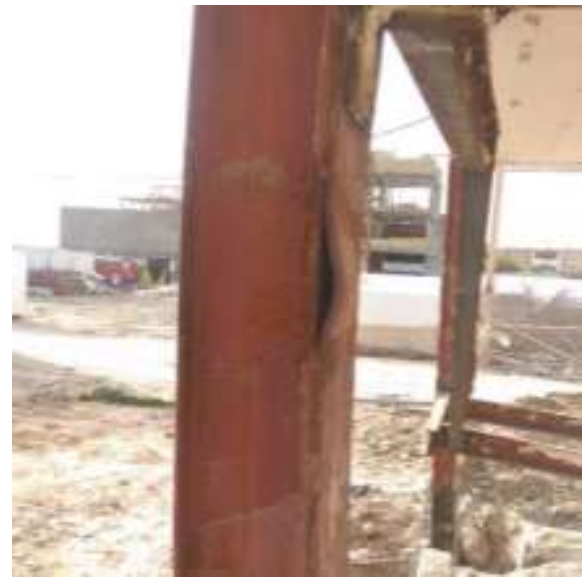

b. Local buckling of a strengthening plate between welding connections to column profiles

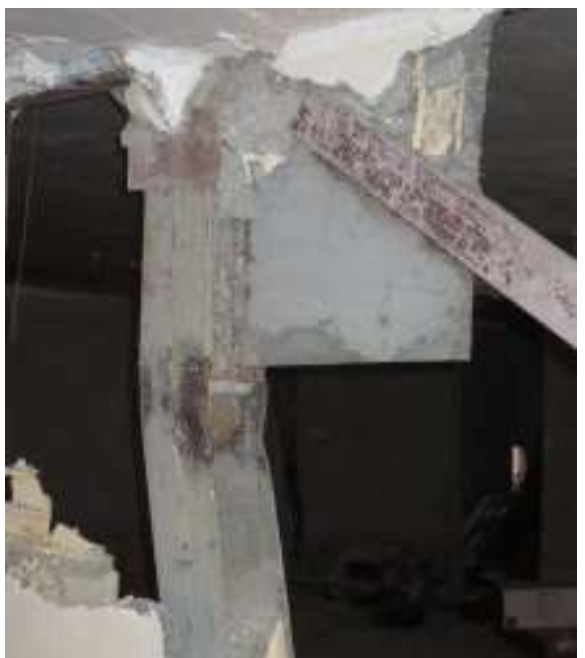

d. Local buckling at the connection region to gusset plate 
Figure 12 presents a percentage of buildings that at least one of their elements sustained the mentioned damages in MRF or braced direction. According to this figure, at least one plastic hinge was observed in columns of nearly $70 \%$ of surveyed steel buildings which were in the retrofitting process. Moreover, in approximately $30 \%$ of buildings, at least one column experienced localized plasticity and deformation. Local buckling of columns was another prevalent damage in steel buildings (about 15\% of buildings experienced this damage), and global buckling of columns was rarely observed in buildings included in the retrofitting program. As shown in Figure 12, the formation of plastic hinges is the most prevalent damage in the MRF direction of steel buildings. The correlation between residual drift and observed damages can present a useful index for post-earthquake assessment of buildings. Therefore, Figures 13a and $13 \mathrm{~b}$ establish such a correlation between the average measured residual drift ratios of each story of investigated buildings and the percentage of observed plastic hinges with different severities. The average value of residual drift ratio in the first story is approximately $0.8 \%$, which is significantly greater than the value of this parameter in the second story of these buildings (this shows the formation of soft and weak-story in the first story of buildings). Besides, the observed residual drift in other stories is negligible. Figures 13a and $13 \mathrm{~b}$ reveal that the percentage of columns that experienced plastic hinges substantially decreases in upper stories so that almost no hinges are observed in the fourth and fifth stories. Most of the other damages to the buildings took place in the first story, and except for some moderate and slight plastic hinges, there is no damage in columns of upper stories.

The main damages in the braced direction were: global buckling of braces, fracture of welds (brace to gusset plate or gusset plate to column web), column web tearing, buckling the beam of braced span (in spans that are detached from the diaphragm), local buckling between batten plates of a brace, and lateral-torsional buckling of beams in eccentrically braced frame spans. Fracture of a brace to gusset plate weld or gusset plate to column web weld was one of the prevalent observed damages in steel buildings' braced direction. The weld fracture at the brace to the gusset plate was caused by poor welding. Also, fracture of gusset plate to column web weld stems from poor welding and the absence of gusset plate to the beam's bottom flange weld. In cases where the gusset plate welding to the column web had an acceptable quality, the column web tore due to its insufficient thickness. Figure 14 shows different types of damages in steel buildings in the braced direction.

According to Figure 12, braces buckling is the most prevalent damage in the braced direction of steel buildings. In most cases, this damage occurred in the first story, and in a few buildings, this type of damage was observed in upper stories. Generally, this phenomenon is due to the development of greater shear forces in the first story compared to other stories and the higher slenderness of braces in this story. According to Figure 12, more than $45 \%$ of steel buildings at least experienced one brace buckling, approximately $25 \%$ suffered welding fracture, and nearly $10 \%$ of buildings' suffered columns web tearing where the gusset plate connected to the web. Nearly $15 \%$ of buildings with eccentrically braced frames sustained torsional-lateral beam buckling. Similar to MRF direction, in the braced direction, there is a correlation between the average measured residual drift ratios and the percentage of influencing damages (brace buckling, fracture of a brace to gusset plate weld, and fracture of gusset plate to column web weld) to the residual drift ratio (Figures 13c and 13d). These figures indicate the concentration of damages in the first story of buildings, leading to a residual drift ratio of more than 2.5 times of this parameter in the second story. 

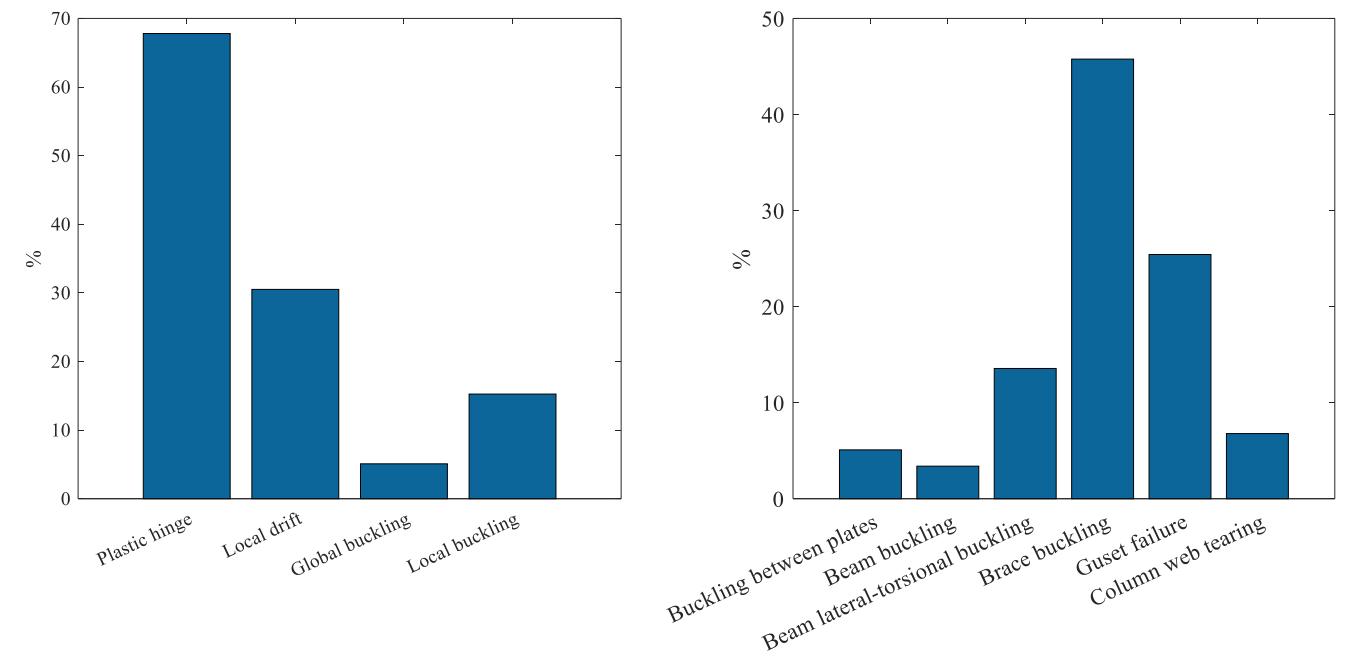

a. Types of columns damage in moment-resisting frame direction

b. Types of damages occurred in the braced direction Fig.12. Percentage of steel buildings that at least one of their columns or braces experiences the mentioned damages
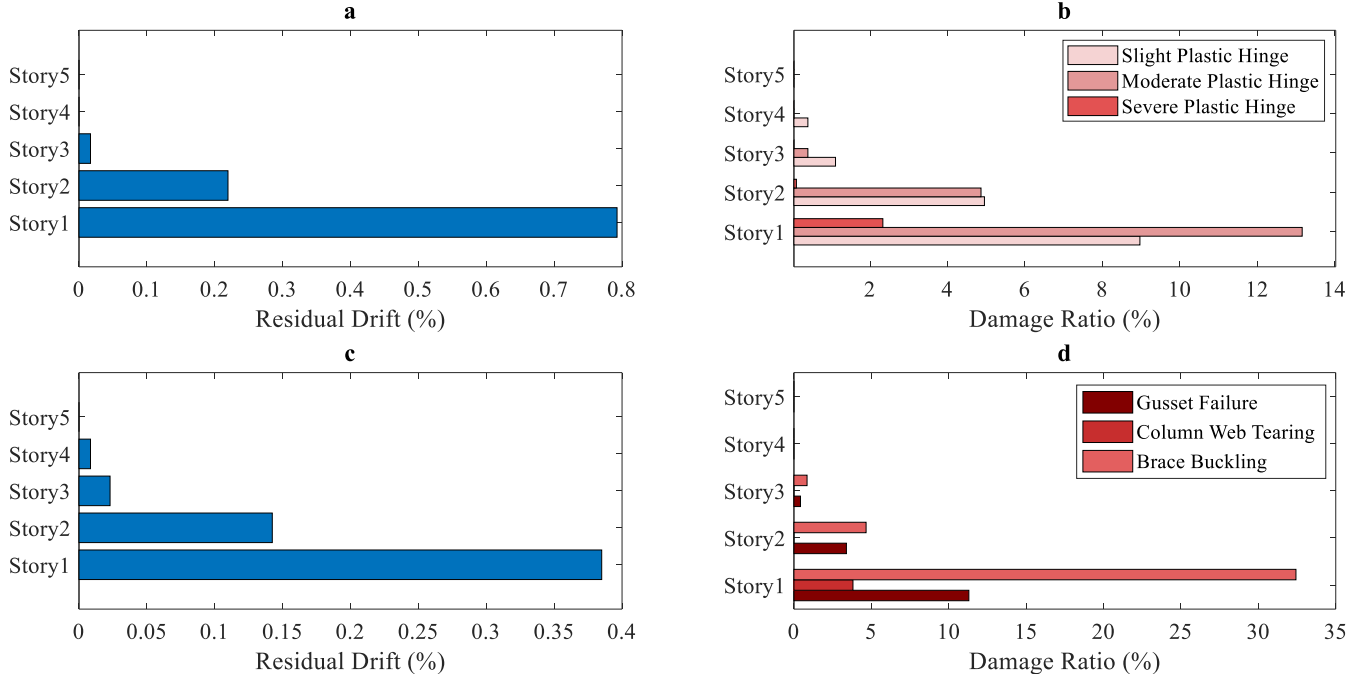

Fig.13. Residual drift ratios and prevalent damage percentages in each story of steel buildings. a. residual drift ratios in MRF direction b. percentages of prevalent damages (plastic hinges) in MRF direction c. measured residual drift ratios in braced direction d. percentages of influencing damages on drift ratio in braced direction

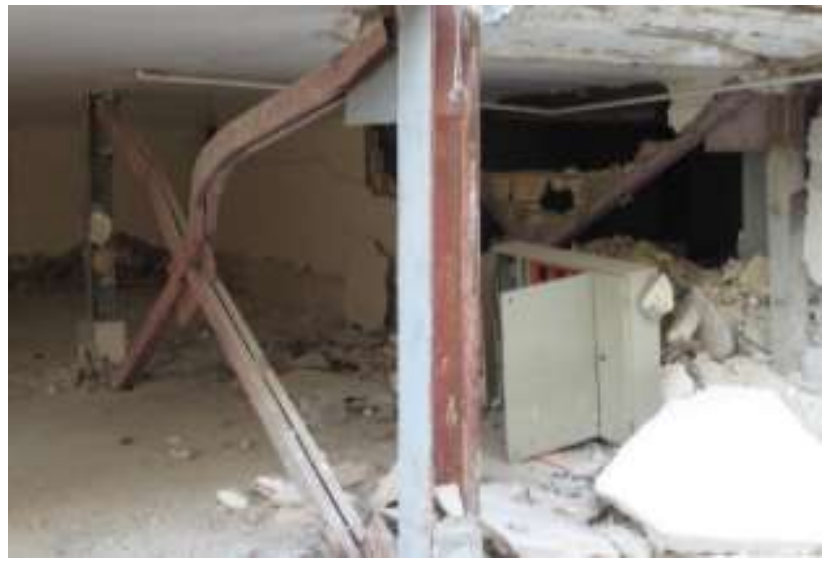

a. Brace buckling

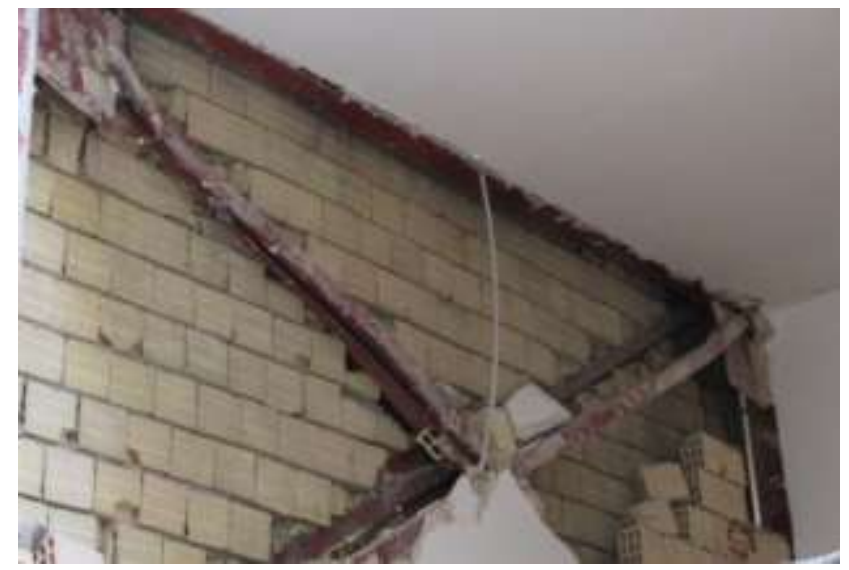

b. Buckling of bracing element between batten plates 


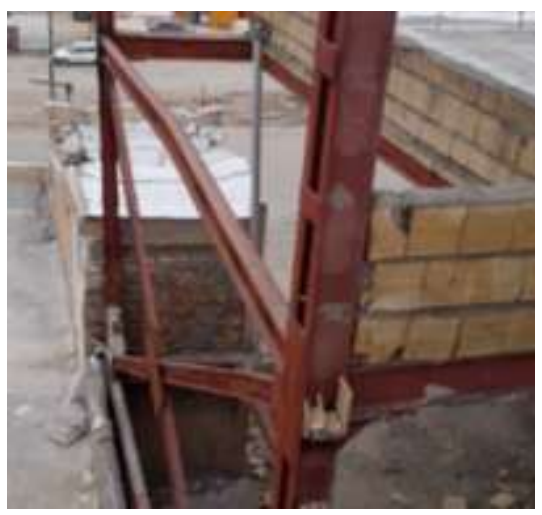

c. Buckling of a beam in the bracing span

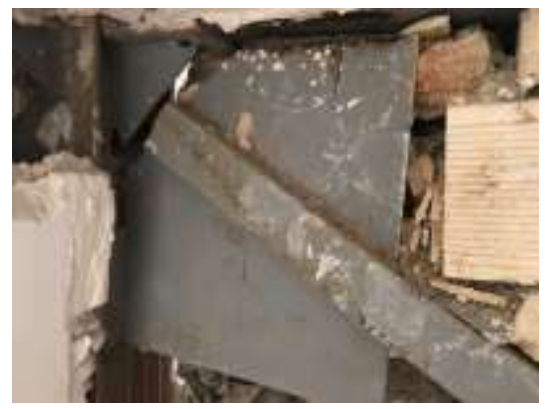

f. Gusset plate to beam weld fracture and damage to the weld of gusset plate to column

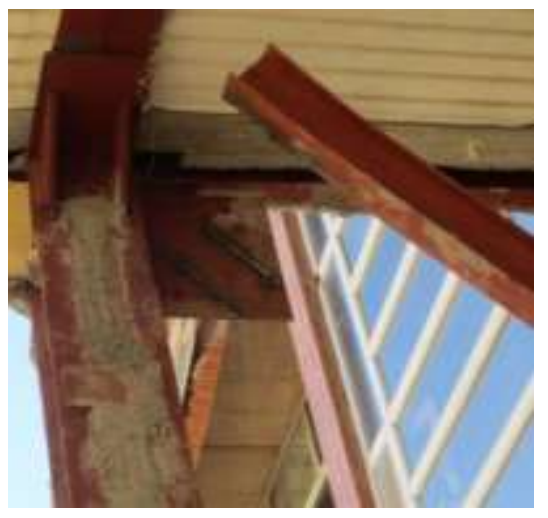

d. Brace to gusset plate weld fracture

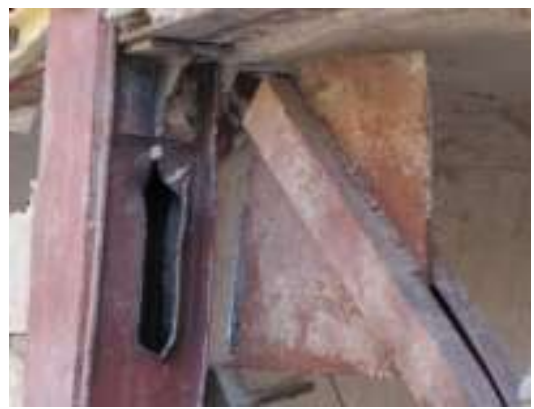

g. Column web tearing in the connection to gusset plate region

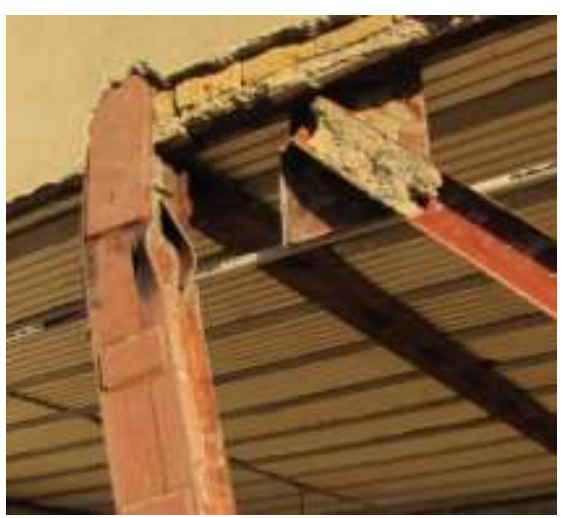

e. Column web tearing in the connection to gusset plate region and local buckling of column flanges

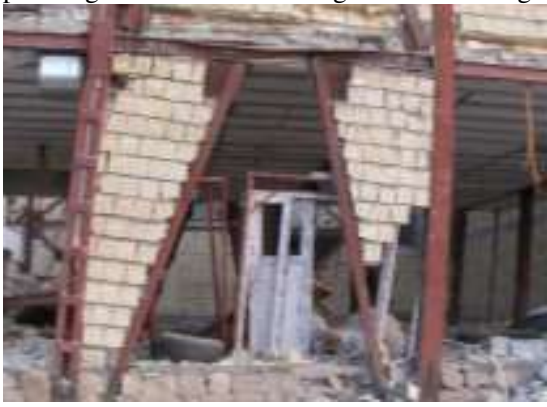

h. Torsional-lateral buckling of link beam

\subsection{Reinforced concrete buildings}

\subsubsection{Construction practice of reinforced concrete buildings}

Moment-resisting frame is the most common lateral load-resisting system in RC buildings of Sarpol-e Zahab city. Since almost all RC buildings have been constructed in the last 10 years, they were expected to be built according to the latest codes and instructions; however, some construction deficiencies make them prone to damage. The low compressive strength of concrete can be considered as the main defect in RC buildings. This deficiency was observed in most of the RC buildings. Figure 15 shows the cumulative distribution function (CDF) of compressive strength of 40 and 50 cylindrical concrete samples of beams and columns of investigated RC buildings, respectively. As it is evident, on average concrete compressive strength of beams and columns is less than $15 \mathrm{MPa}$, which is less than the prescribed values in National Building Regulations, Part 9: Design and Construction of Reinforced Concrete Buildings (ONBR 2013b) and ACI 318-14 (2014) (according to these codes the minimum permitted compressive strength of concrete is $20 \mathrm{MPa}$ and $17 \mathrm{MPa}$, respectively). More critical are buildings with concrete compressive strength of about $5 \mathrm{MPa}$. 

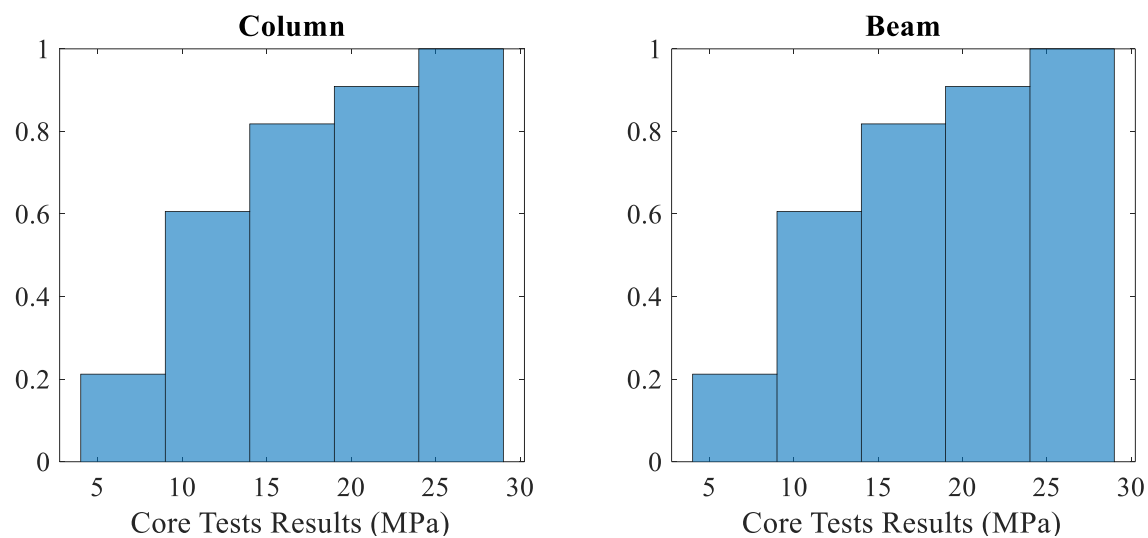

Figure.15. Compressive strength of beams and columns obtained through testing the extracted cylindrical cores

High values of beams and especially columns concrete cover thickness was another prevalent defect in RC buildings. The concrete cover of members in some buildings reached $8 \mathrm{~cm}$. Another flaw observed in almost all RC buildings was implementing ties and stirrups with short $90^{\circ}$ hooks at both ends instead of $135^{\circ}$ seismic hooks. In some cases, this defect led to the stirrup opening and severe damage to RC columns' concrete cover and core. Furthermore, poor confinement details such as wide spacing of transverse reinforcement, inadequate lap splice length, and absence of transverse reinforcement at column-beam joints were other common defects in RC buildings. All these deficiencies make it impossible to consider these buildings in the ductile category. However, due to complying with some seismic design criteria, these buildings' assumption as non-ductile cannot be close to reality. Thus, these buildings can be considered semi-ductile. Figure 16 shows the construction practice of RC buildings.

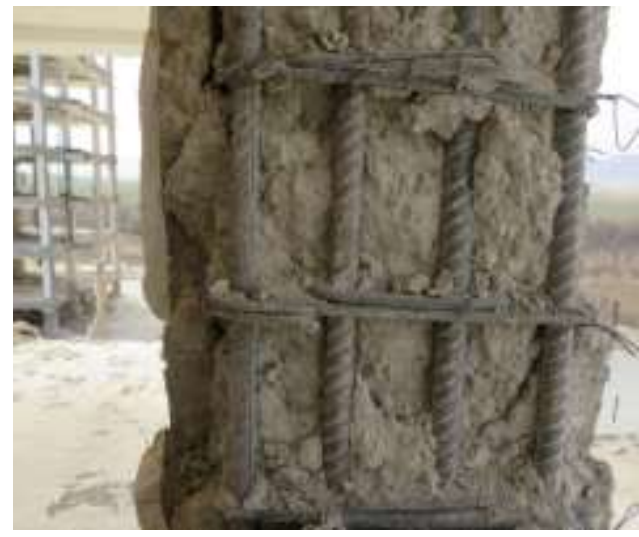

a. Implementing stirrups with $90^{\circ}$ hooks instead of $135^{\circ}$ hooks

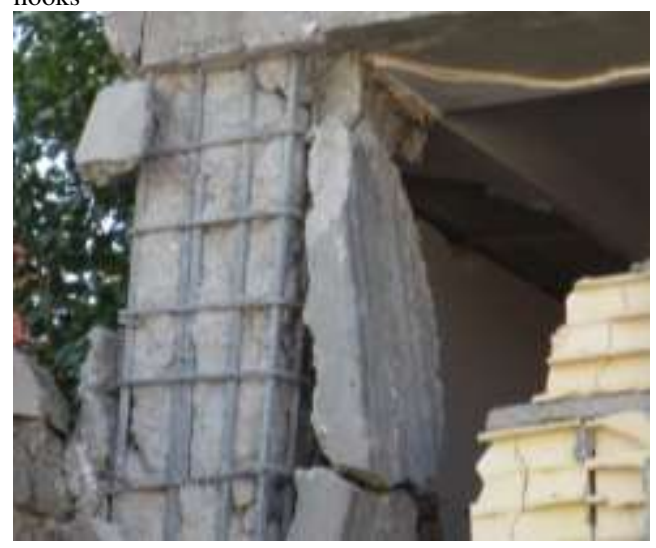

c. High concrete cover thickness of a column

Fig.16. Construction practice of RC buildings and their common observed deficiencies

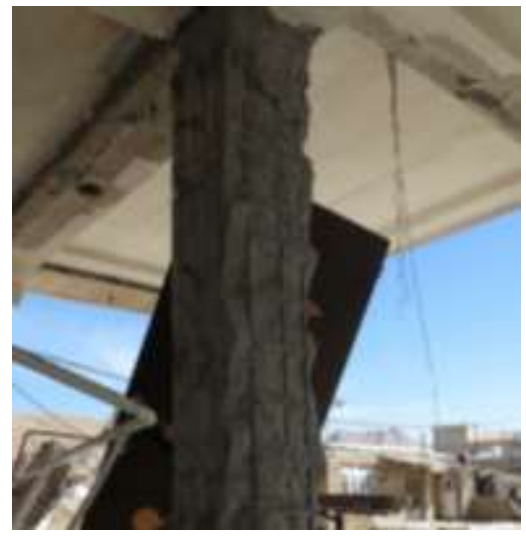

b. Lack of confining details in the critical regions of column

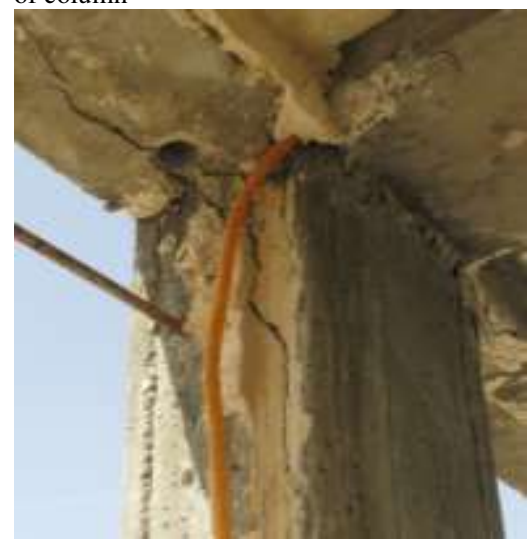

d. Passing a pipe from the critical region of a beam 


\subsubsection{Damages}

Generally, the observed damages in RC buildings were as follows: damages in columns include a flexural crack, shear crack, flexural-shear crack, vertical (splitting) crack, concrete cover spalling, concrete cover crushing, and concrete core destruction. Damages in beams include a flexural crack, shear crack, and flexural-shear crack. Damages in beamcolumn joints include a hairline crack, diagonal crack, severe diagonal crack, damage and destruction of concrete cover, and severe damage of concrete core.

In contrast to the steel structures, damages in RC buildings are concentrated in both first and second stories. Therefore, the soft story was not observed in the first story of RC buildings. Most of the columns' damages were due to the low compressive strength of concrete, wide spacing of transverse reinforcement, and faulty construction detailing. For instance, the end hook angle of stirrups was not followed the code's instructions. Figure 17 shows some damages that occurred to the RC columns.

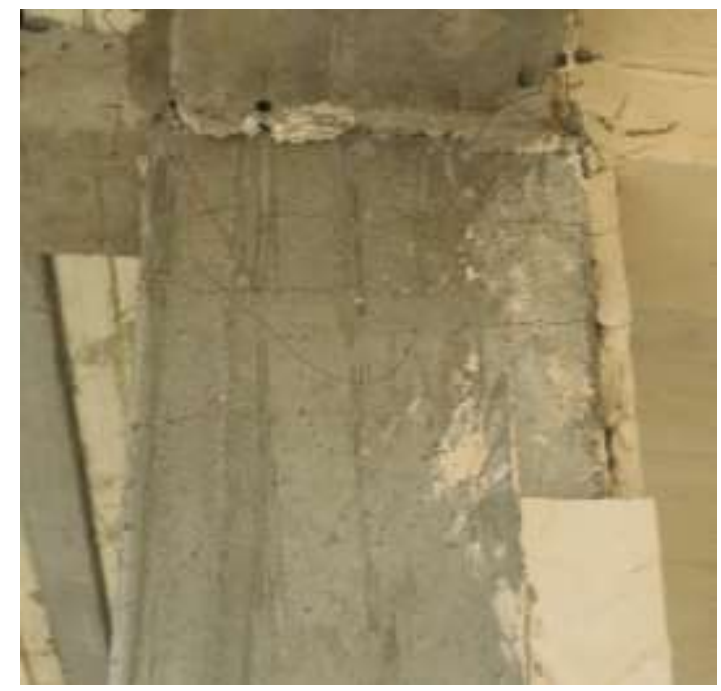

a. Flexural crack

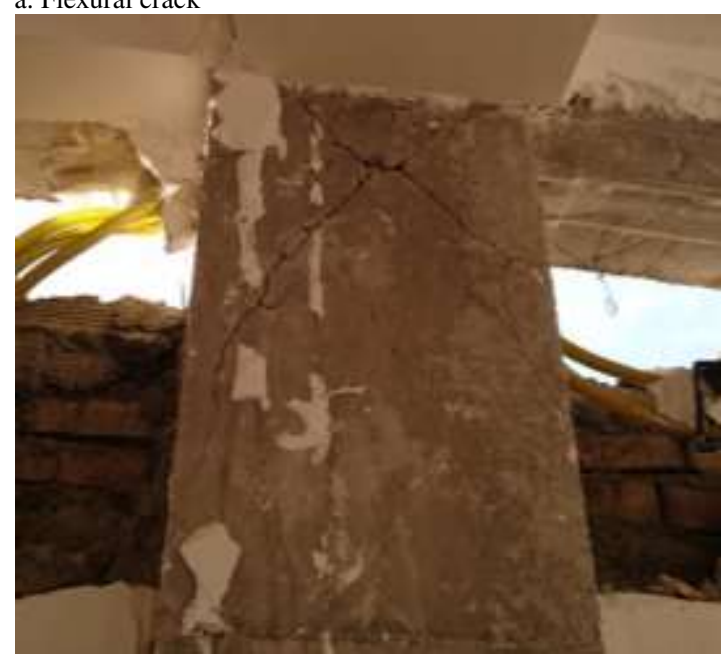

c. Shear crack at top of the column due to the diagonal developed force in infill walls
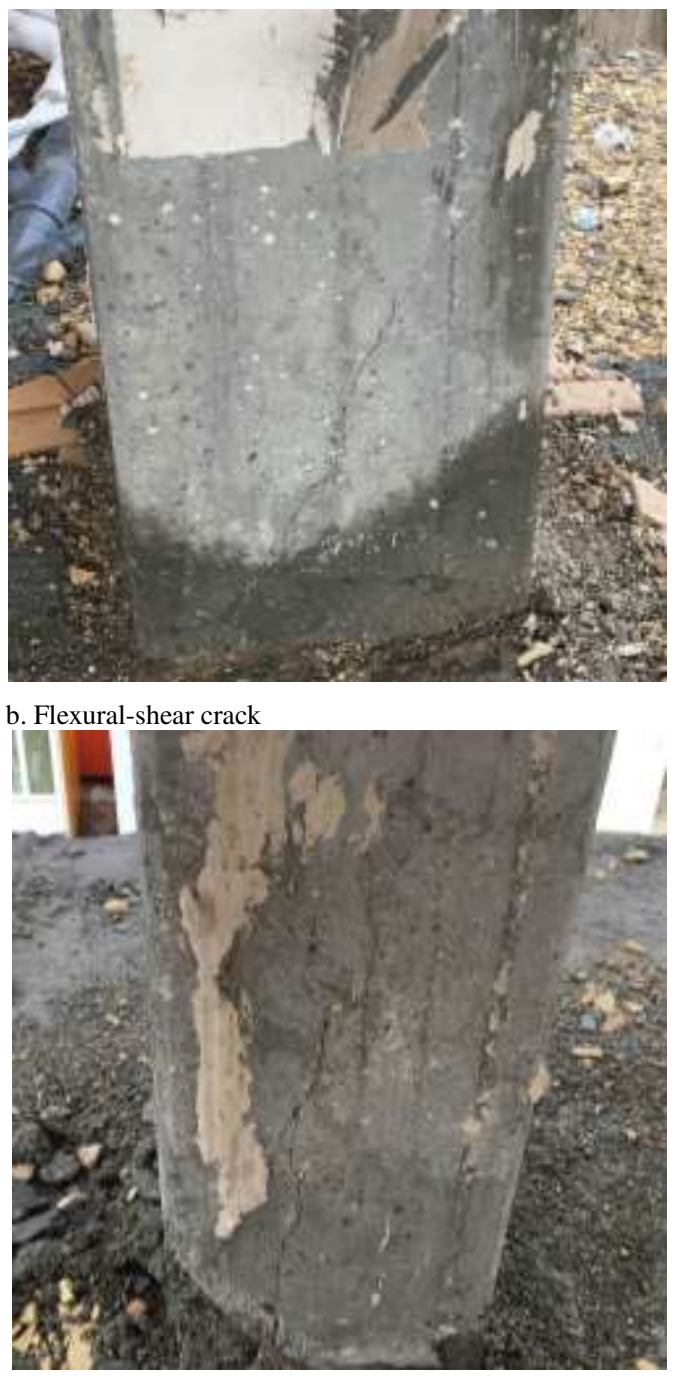

d. Vertical (splitting) crack 

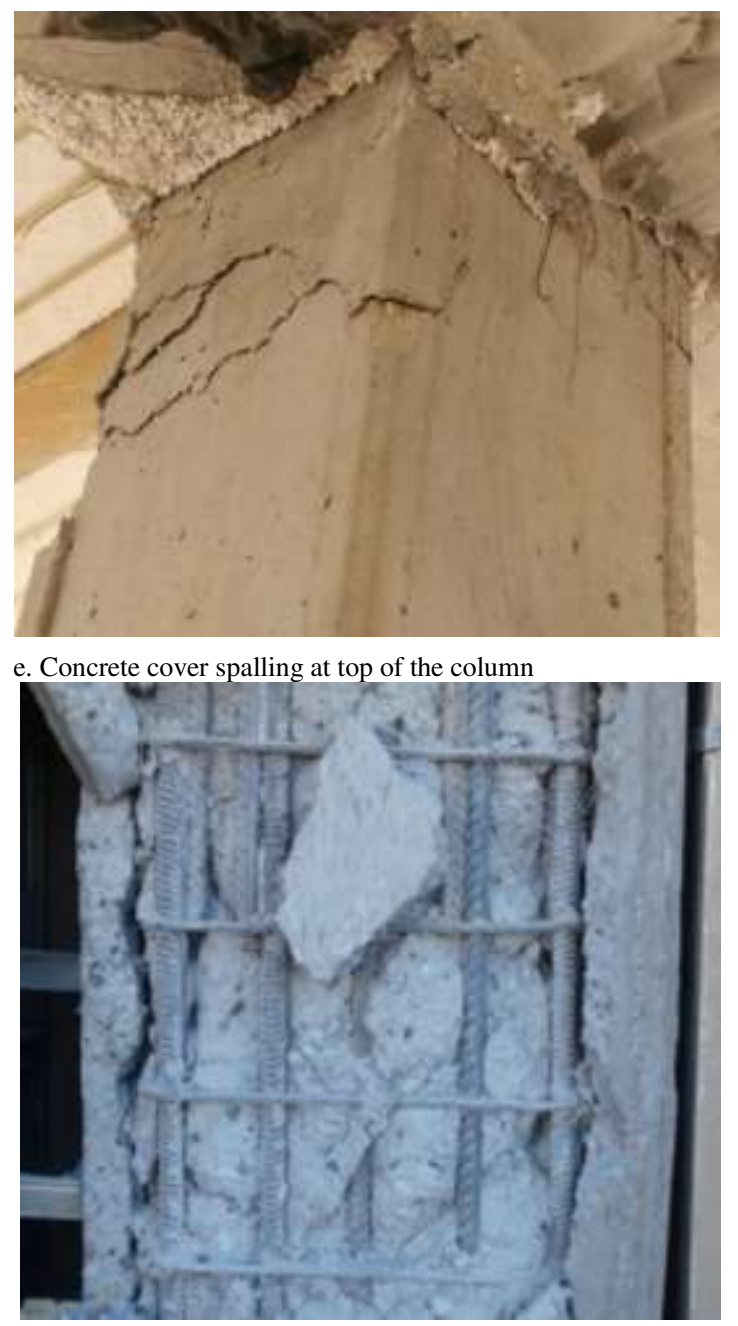

g. Partial crushing of concrete core and severe crushing of concrete cover

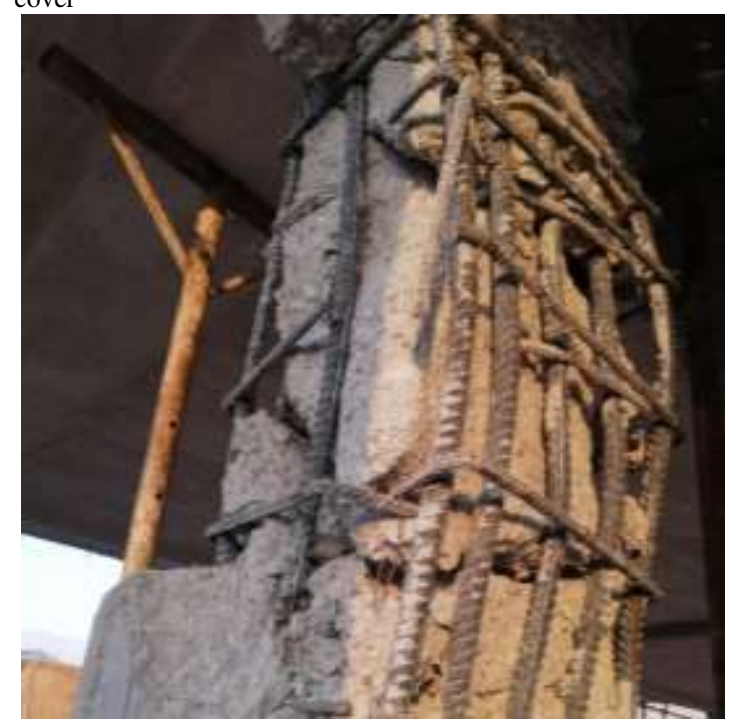

i. Concrete core destruction, opening and rupture of stirrups, and longitudinal reinforcement buckling

Figure.17. Some observed damages in RC columns
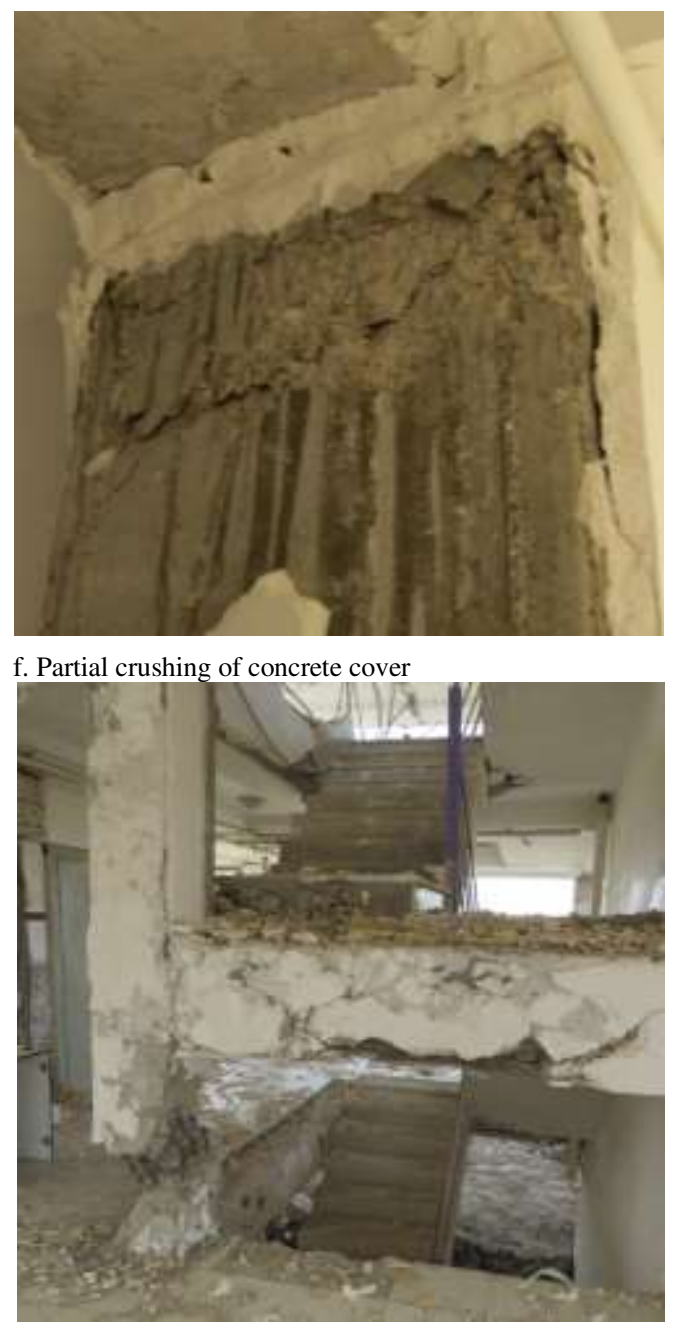

h. Column concrete core destruction due to formation of short column

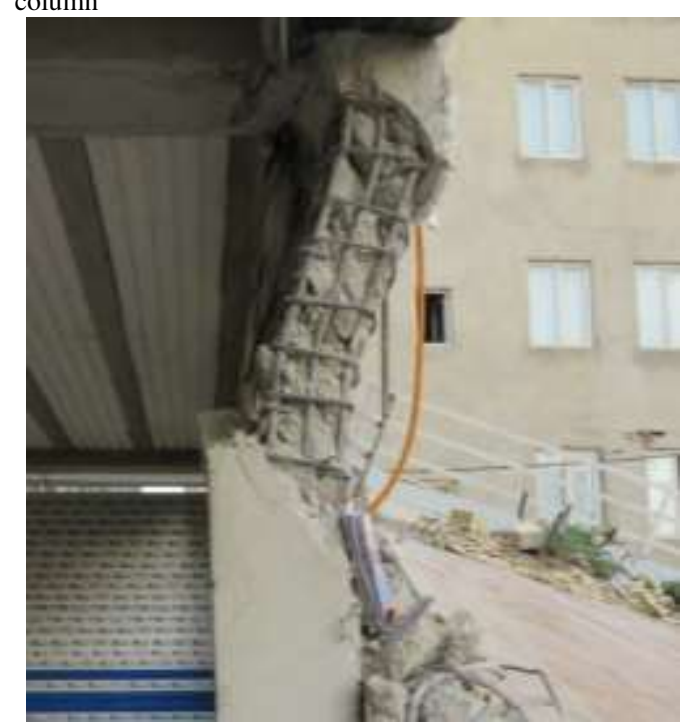
j. Concrete core destruction and buckling longitudinal reinforcement 
Figure 18 presents a percentage of buildings that at least one of their columns or beams experienced the mentioned damages. The flexural crack of columns, concrete cover crushing, and shear crack were the most prevalent damages in columns so that in more than $60 \%$ of the investigated buildings, at least one of the columns experienced these damages (Fig.18). Shear cracking and severe damage of columns surrounding the staircase due to the short column formation were other prevalent damages. Besides, owing to the transfer of the developed diagonal force in the infill walls to the adjacent columns and producing concentrated shear force at the ends of them, shear cracks at the ends of columns (especially top of the column) were observable in almost all buildings that had infill walls. Another common type of damage was concrete cover spalling at the top of the columns. According to the investigations, columns' concrete cover spalling occurred in more than $25 \%$ of RC buildings. Columns concrete core destruction was the most critical damage taken place in RC columns. According to the research, at least one of the columns of more than 20\% of RC buildings sustained severe damage to the concrete core or destruction. This can be due to poor details, inadequate confinement, and low compressive strength of concrete. Finally, vertical cracks caused by the low compressive strength of concrete and flexural-shear cracks can be pointed out as other prevalent columns damages.

The main observed damages in beams were due to the low compressive strength of concrete and the lack of transverse reinforcement. In addition, some construction problems, such as passing facility pipes from a cross-section of beams, led to more vulnerability of beams. Because of the ceiling, crack detection in the middle parts of the story (ceiling) was impossible or difficult. Nevertheless, in more than $70 \%$ of RC buildings, at least one beam experienced shear crack, and in more than $45 \%$ of RC buildings, at least one beam suffered from the flexural crack. One of the most prevalent damages observed in beams was shear cracks at the ends of beams, which occurred due to the transfer of concentrated shear force diagonally developed in infill walls. Generally, similar to steel buildings, in RC structures, due to non-conforming to the weak beam-strong column principle (according to National Building Regulations, Part 9: Design and Construction of Reinforced Concrete Buildings (ONBR 2013b) and ACI 318-14 (2014) compliance with this principle for ordinary and intermediate MRFs is not necessary), damages of beams were significantly less than the columns damages. Figure 19 indicates observed damages in RC beams.

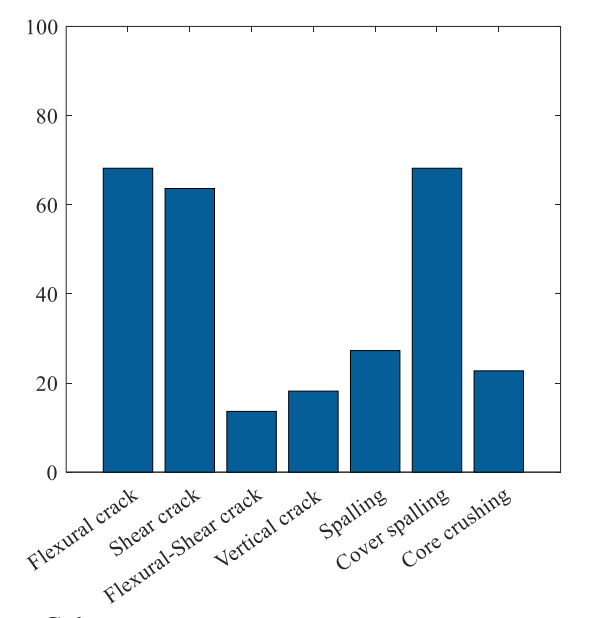

a. Columns

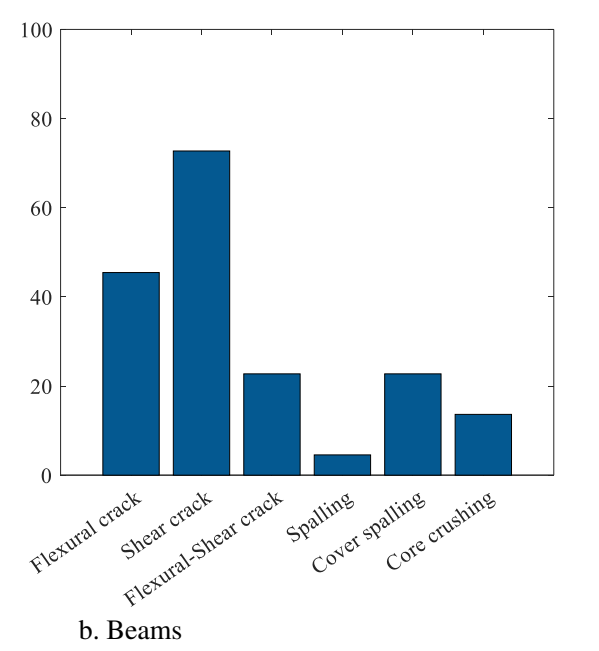

b. Beams 


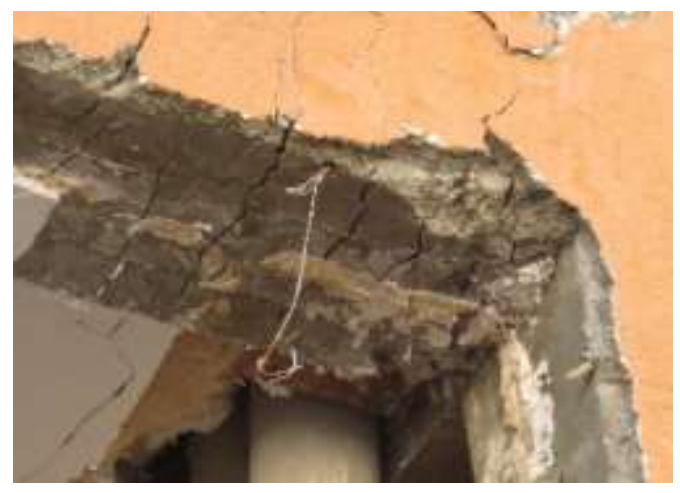

a. Flexural cracks in a beam

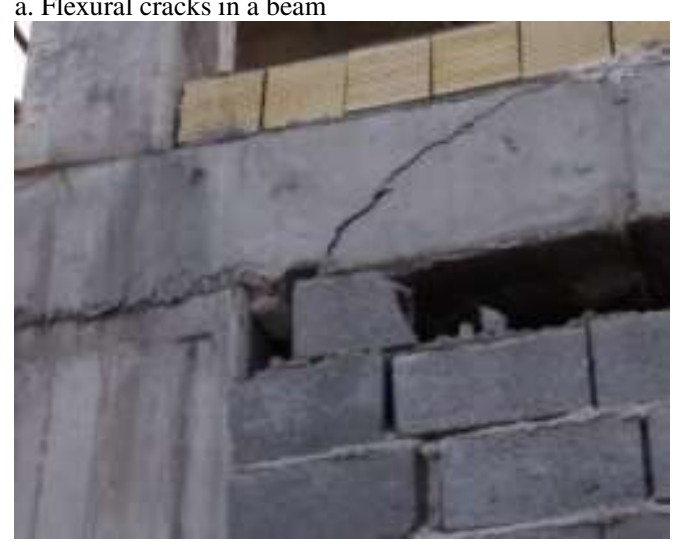

c. Shear crack in a beam caused by the developed diagonal force in an infill wall

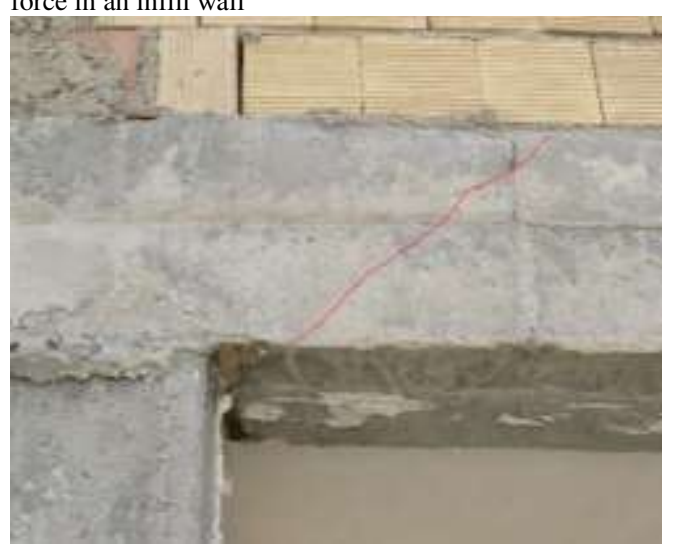

e. Shear crack

Figure.19. Observed damages in RC beams

Figure 20 shows some damages observed in beam-column joints. Like beams and columns, a percentage of buildings that at least one of their beam-column joints sustained the prevalent mentioned damages is presented in Figure 21. Figure 21 shows that, except for severe damage to the concrete core, other damages were prevalent in RC buildings. In more than $35 \%$ of buildings, at least one joint experienced hairline cracks, and in more than $25 \%$, at least one joint suffered from the diagonal crack or concrete cover crushing. The absence of transverse reinforcement and poor detailing were the main reasons for damage in beam-column joints.

Based on observations, it appears that shear failure prevailed in many of these buildings instead of flexural failure due to construction defects. Thus, there was no considerable residual drift in almost all RC buildings, unlike steel structures. Hence, using a residual drift as an index for a level of occurred damages to a building is not possible. 


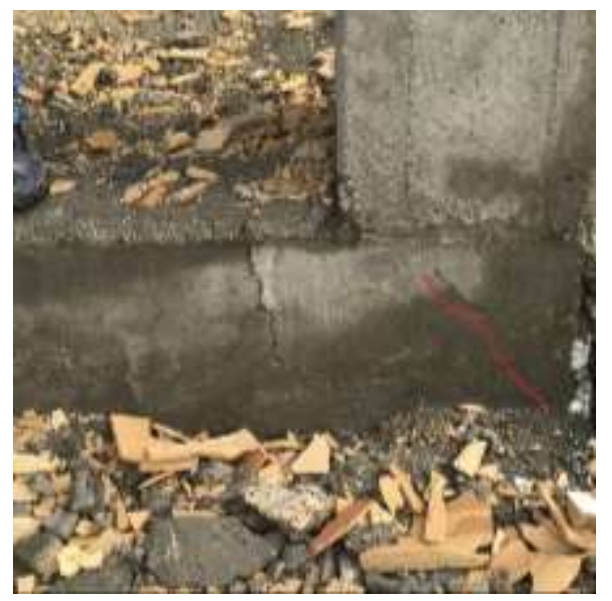

a. Hairline cracks

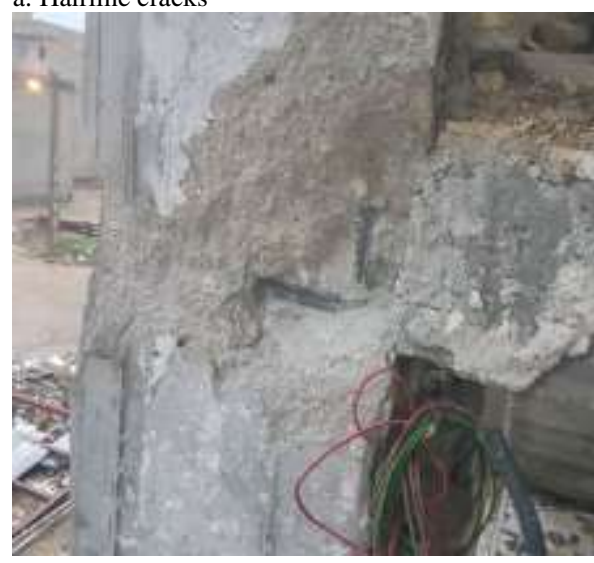

c. Concrete cover crushing

Figure.20. Observed damages in beam-column joints

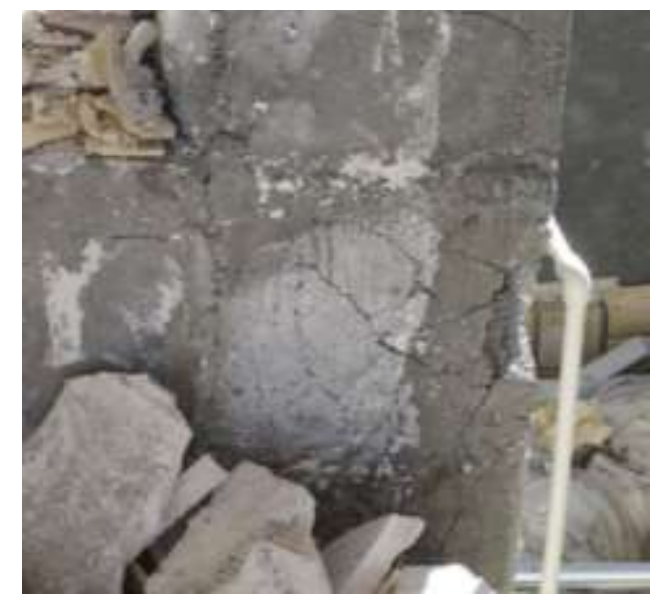

b. Diagonal and hairline cracks

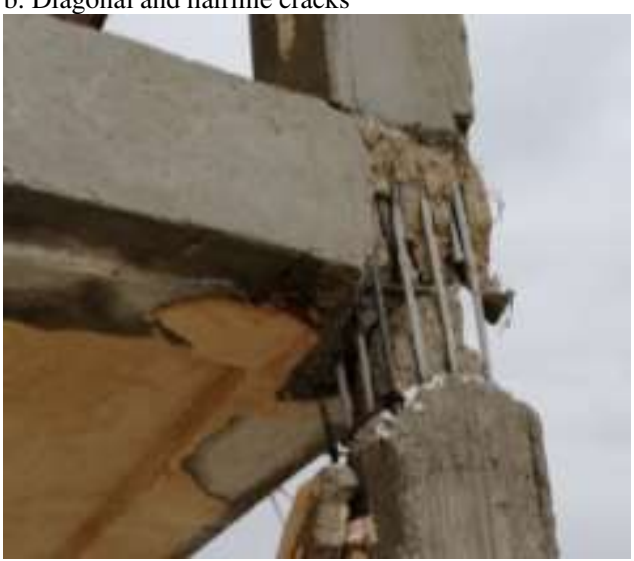

d. Severe damage and destruction of concrete core

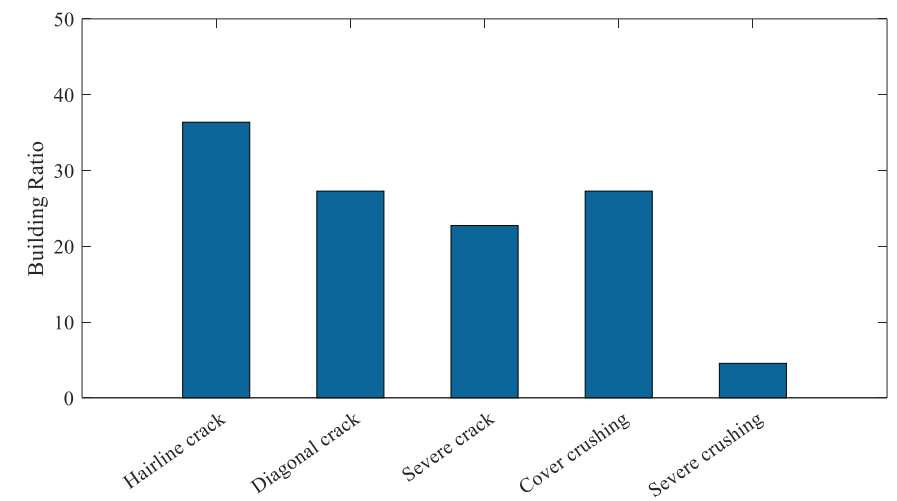

Figure.21. Percentage of RC buildings that at least one of beam-column joints sustained the mentioned damages

\section{Non-structural damages in different buildings}

Non-structural elements include interior partition walls, exterior walls (used in most buildings), and infill walls. Since non-structural elements of buildings were constructed without any wall post for out-of-plane failure, they collapsed totally or partially or suffered severe damages due to building lateral displacement. Besides, there was no separation and protection between non-structural and structural (beams and columns) elements. Hence, by imposing lateral forces on the stories and their deformation during the earthquake, in-plane and out-of-plane forces were imposed on nonstructural elements. In cases that non-structural elements were strong and restraint at boundaries (masonry infill walls), they contributed to resisting lateral forces and buildings remained undamaged. In cases that the used materials were 
weak and without adequate out-of-plane stability, non-structural elements (partitions) suffered severe damages and usually collapsed due to the imposed out-of-plane acceleration. Figure 22 shows the common construction practice of walls in Sarpol-e Zahab city.

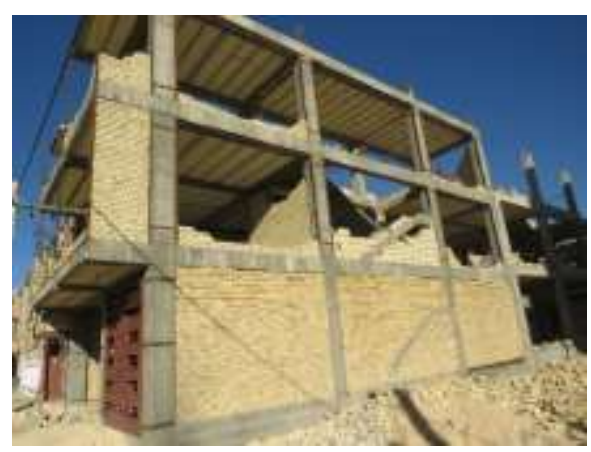

a. Using solid brick walls without separation from beams and columns (masonry infill walls)

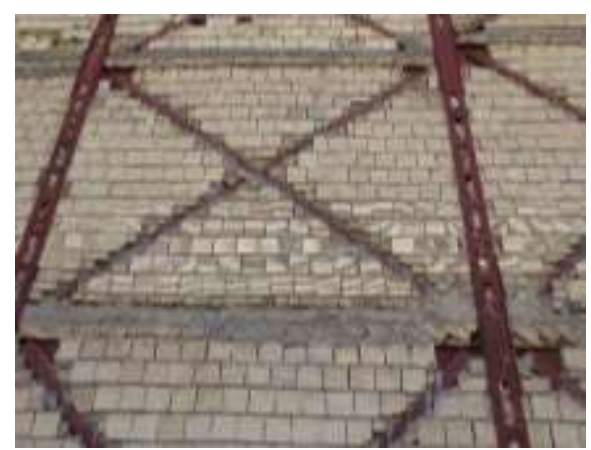

b. Using hollow brick walls without separation from beams and columns (these walls cannot be considered as a structural element)

Figure.22. Construction practice of walls in steel and RC buildings

According to the observed damage of walls and their prevalence, they classify into 3 categories: slight damage, severe diagonal or sliding crack, and partial or total collapse of the wall. Figure 23 shows samples of these damages. It is worth noting that the length ratios of damaged walls to whole walls of that story in the considered direction are utilized to determine the percentage of damaged walls.

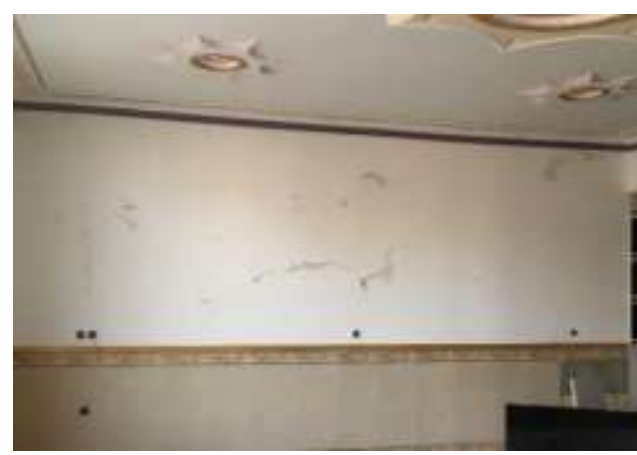

a. Slight damage

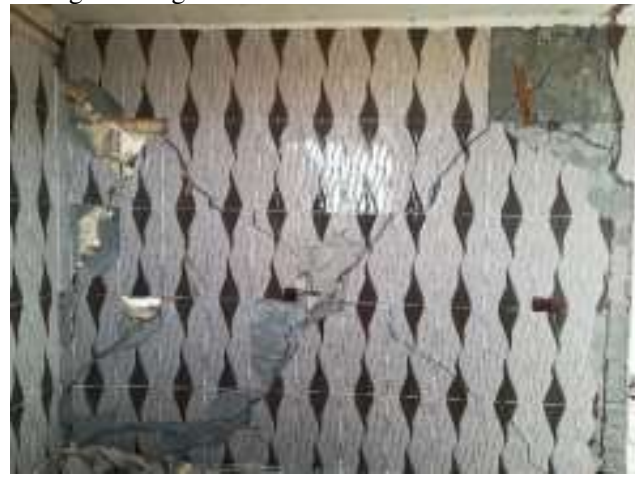

c. Severe diagonal crack

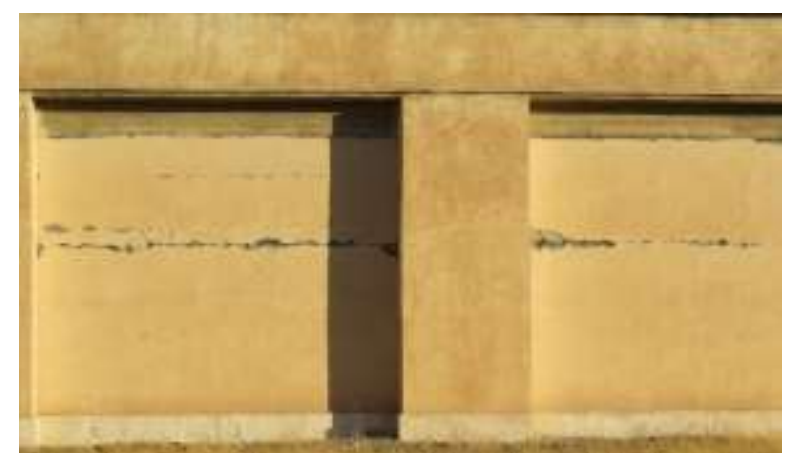

b. Severe sliding crack

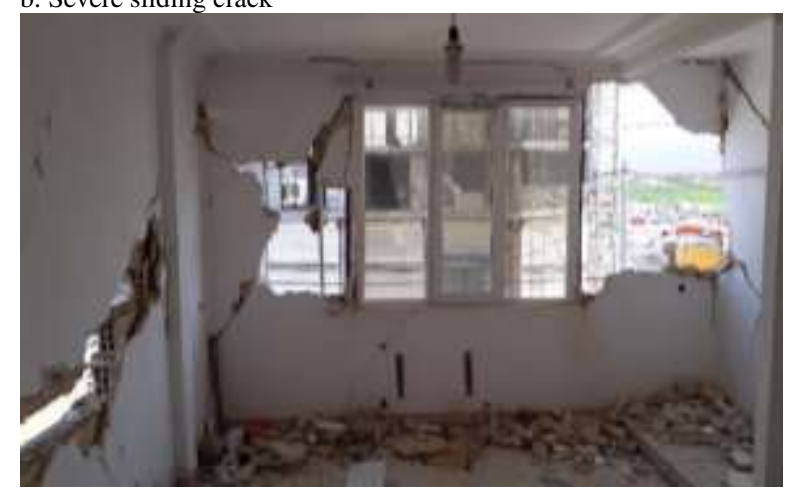

d. Partial collapse of walls

Figure.23. Observed damages in steel and RC buildings walls

The damage to non-structural elements is a function of maximum experienced drift during an earthquake; however, it is impossible to determine this parameter in field investigations of damaged buildings after the earthquake. So this research investigated the relationship between the maximum residual drift and the severity and extent of damage in non-structural elements. Figure 24 indicates the average drift ratios of each story of steel buildings in MRF and braced directions corresponding to the average percentage of different types of occurred damages to walls and partitions. It is evident that there is a direct relationship between the occurred damages to non-structural elements and buildings' 
residual drifts. Like structural elements, as the drift ratio of a story increases, the damage extent and severity in nonstructural elements also increase. Thus, the first story of buildings experienced the most severe damages. Furthermore, as shown in Figure 24, the percentage of partially or totally collapsed walls is more than walls that suffered from diagonal or sliding cracks or slight damages. Hence, it can be concluded that the lack of out-of-plane restrictions for walls is the main reason for this failure mode. A comparison between the percentage of damaged walls in MRF and braced directions demonstrates that the possibility of damage occurring in the MRF direction is more than the braced direction, which can be due to the greater displacement demand and residual drift in the MRF direction.
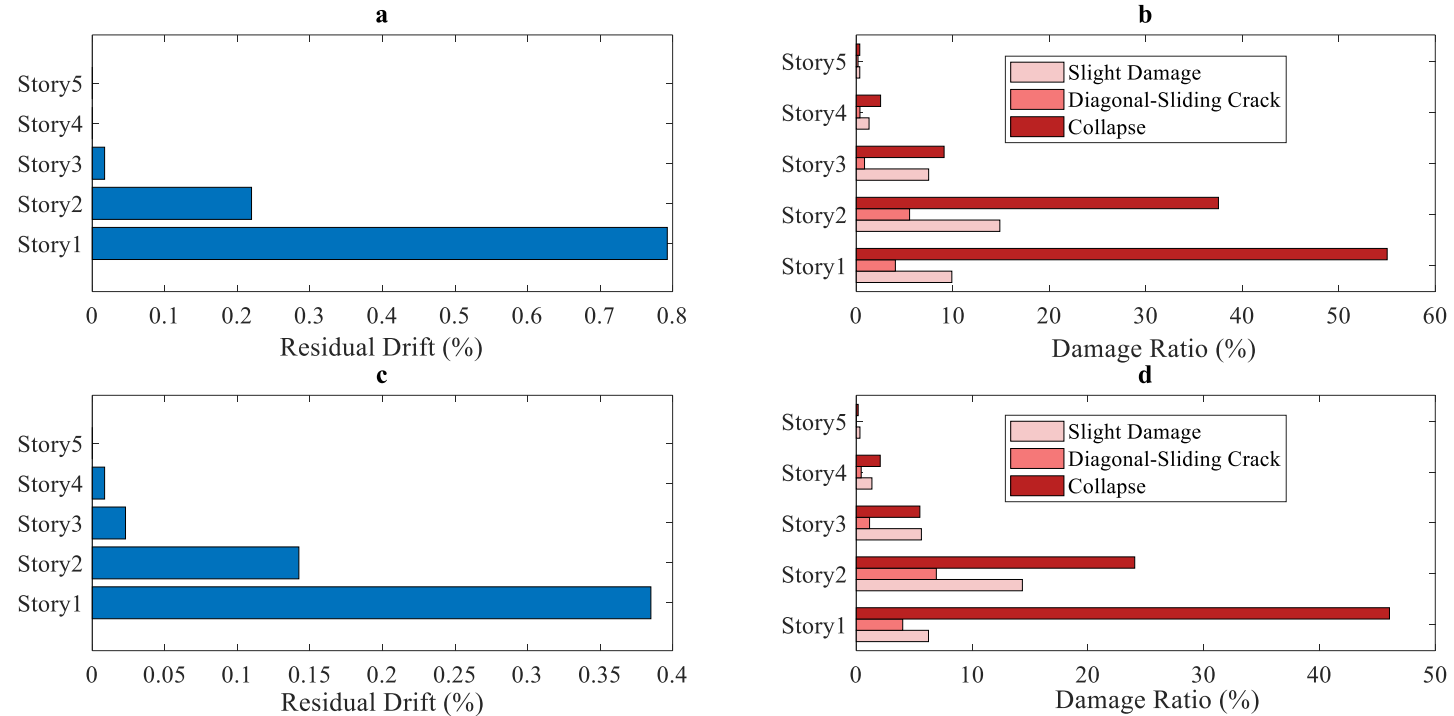

Fig.24. Residual drift ratio and percentage of various non-structural damages in different stories a. residual drift ratio in MRF direction b. percentages of various wall damages in MRF direction c. residual drift ratio in braced direction d. percentages of various wall damages in braced direction

As mentioned earlier, residual drift was negligible due to the low ductility demand of RC buildings. Therefore, a relationship between the non-structural damages and the most general structural damages (flexural crack, shear crack, and concrete cover crushing) is investigated (Fig.25). Figure 25 indicates that most of the structural and non-structural damages took place in RC buildings' first and second stories. These damages developed less severely in the third story, and the upper stories approximately remained intact. Also, there is a good correlation between the severity and extent of structural and non-structural damages in different stories.

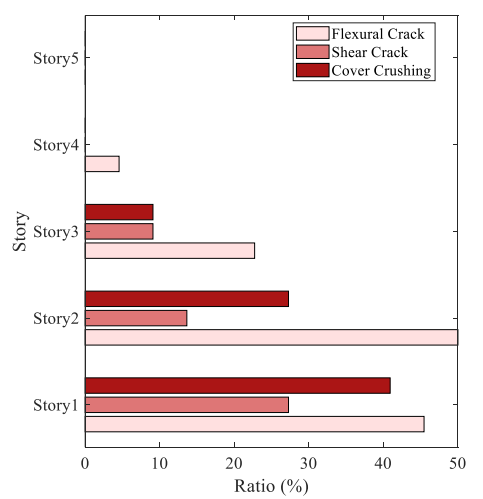

a. Prevalent occurred damages in columns of different stories

Figure.25. Correlation between the structural and non-structural damages of RC buildings

Stairs are another element that was significantly affected by the earthquake. Although these diagonal elements are not considered as a lateral resisting system in the design, they have a considerable lateral bearing capacity and, in some cases, have suffered serious damages during the earthquake. The most prevalent structural stair damages observed in steel buildings are as follows: slight and limited damage to the staircase and its connections and total collapse of the 
staircase, which is often due to the fracture of the connection of the staircase beam to other beams or columns. The first type of observed damages consisted of slight damages to staircase beams and especially connections, which seemed to be repairable and reusable with some measures. In some buildings, owing to the fracture of staircase beams to beam or column connections, the staircase collapsed or got unstable in such a way that it was not repairable. Figure 26 shows some observed damages in the stairs of steel buildings. Stair damage is more prevalent in RC buildings compared to steel buildings. The most prevalent structural stair damages observed in RC buildings are concrete cracking and spalling at the stair to ceiling connection region, concrete cover crushing and rebar exposure at the stair to ceiling connection region, and total collapse of the staircase. Figure 27 shows observed frequent damages in the stairs of RC buildings.

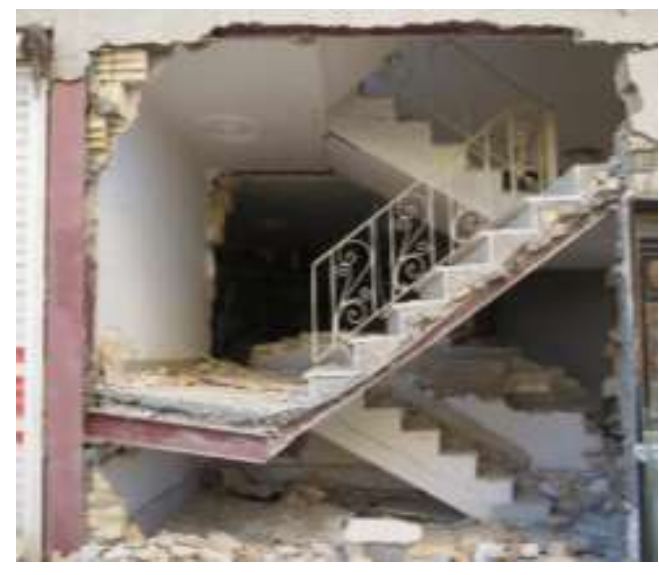

a. Rotation of stair beam to column connection and severe damage to staircase

Fig.26. Occurred damages to the stairs of steel buildings

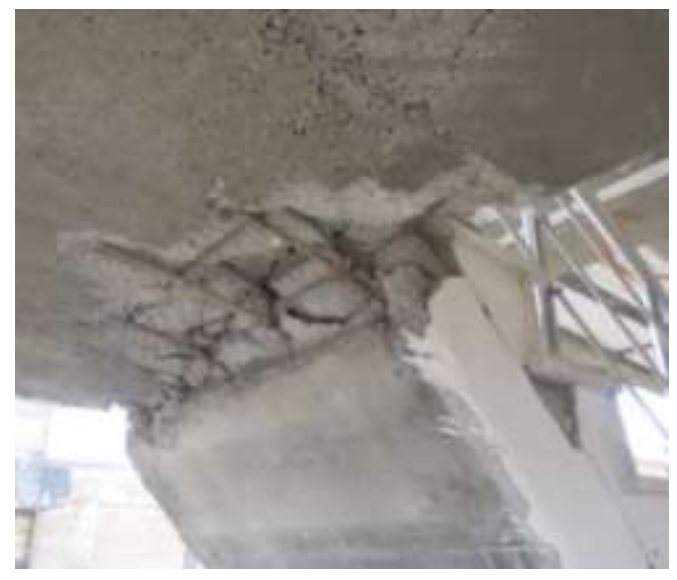

a. Concrete cover crushing and rebar exposure at the staircase to ceiling connection region

Fig.27. Occurred damages to the stairs of RC buildings

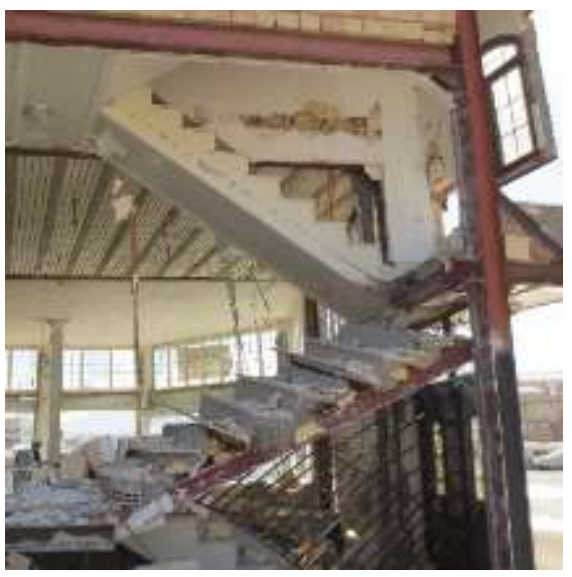

b. Fracture of stair beam to column connection and un-stability of staircase

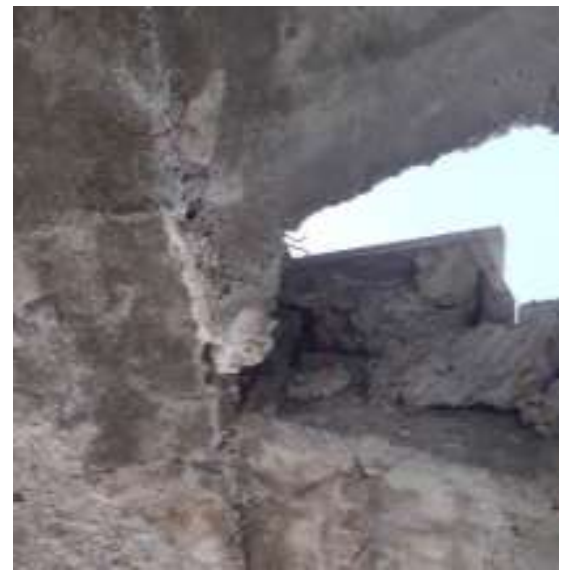

b. Cracking at the staircase to ceiling connection region

Figure 28 shows the percentage of various damages to the staircase of buildings in different stories. According to Figure 28a, connections were fractured, and stairs were destroyed in the first story of more than $20 \%$ of steel buildings. Also, slight stair damage was observed in more than $25 \%$ of the first story of steel buildings. These damages were not observed in the upper stories, and almost no structural damages were found to the stairs. Structural damages to the staircase of RC buildings were more prevalent than the steel buildings in such a way that in most of the buildings, the stairs of the first story experienced structural damages (Fig.28). 


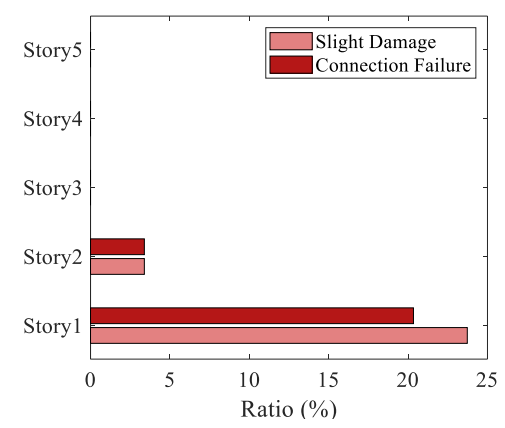

a. Steel buildings

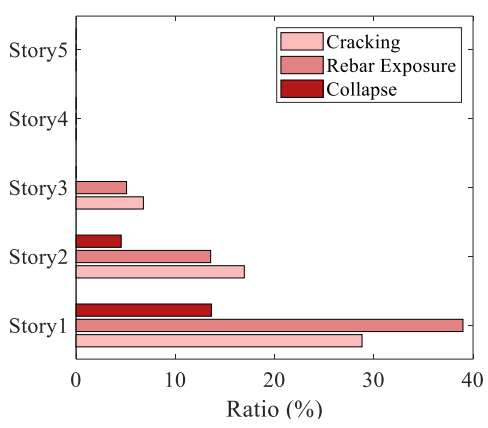

b. RC buildings

Investigations show that the possibility of structural damage in stairs parallel to the MRF direction is more than the braced direction. In fact, in buildings whose stairs were constructed parallel to MRF direction, the staircase experienced more severe damages than buildings whose stairs were constructed parallel to the braced direction. This can be why RC buildings' stairs (which their lateral load resisting was MRF) experienced more damage than steel buildings (in which most stairs were parallel to braced direction).

\section{Damage index (DI)}

Many efforts have been devoted to determine a criterion that could indicate the severity and extent of structural and non-structural damages to buildings after catastrophic earthquakes in recent decades. Generally, global criteria have been defined for the severity of damages in these studies; Thus, the final DI and the classification of damaged buildings based on the severity and extent of occurred damages were not precise, and qualitatively was introduced as DS (e.g., Grünthal 1998, HAZUS 1999, Okada and Takai 2000).

This research introduces a quantitative approach for defining a new DI. For this purpose, a thorough survey is conducted on all structural and non-structural components of 81 damaged buildings. For different types of observed damages in different components and members within considered buildings, corresponding damage indices are defined to represent any members' damage type and intensity mathematically. The range of these weights is chosen based on the authors' judgment, which is based on previous studies, experiences and, experiments. These types of damages and their indices for steel, RC, and non-structural component are defined in Table 1, 2, and 3, respectively. It should be noted that the assigned weight to each type of damage is based on the importance and the risk level of that damage in the considered member for the whole building. Finally, by adding the damage indices of members (columns, beams, braces, and non-structural components) in each story, the DI of each story is calculated. Equation 3 is proposed to calculate the DI of each story for steel buildings:

$$
S D I=\frac{1}{M p d}\left(\sum_{i=1}^{n} \frac{N_{x_{i}}}{N_{x_{t}}} d i_{i}+\sum_{i=1}^{n} \frac{N_{y_{i}}}{N_{y_{t}}} d i_{i}\right)
$$

which $x$ and $y$ represent the lateral load resisting system in each direction of a building, $N_{x}$ (or $\left.y\right)_{i}$ represents the number of structural elements (columns in moment resisting frame direction or braces and connections of braces in the braced direction according to Table 1) suffering from damage type $i$ in each story and direction $x$ or $y, d i_{i}$ is the weight assigned to damage type $i$, and $n$ specifies the number of different types of damages in each direction. It should be noted that in cases where there is more than one type of damage in an element, the most severe observed damage type is considered (e.g., if a column has both plastic hinge and global buckling, the global buckling is considered as the representative damage).

In Equation 3, Mpd is a coefficient (maximum probable damage indices) to normalize DI within 0 to 1 range. This coefficient is obtained by summing the assigned weights to the most severe damage types in the MRF direction (global buckling of a column) and in braced direction (fracture of brace to gusset plate weld and tearing of column web in the connection to gusset plate). This value for the steel structures of this study is 20 . 
Considering that in the examined buildings, due to non-observance of proportioning in the design and construction, major damages occurred only in one of the stories (the first story in steel buildings and the first or second story in RC buildings); So, the global structural damage index (SDI) of a building is considered as the maximum value of damage indices of different stories, which indeed determines the overall behavior of the structure.

$$
B S D I=\max \left(S D I_{j}\right)
$$

Table 1 Prevalent damages in steel buildings, the assigned weights to the damages, and sample figures

\begin{tabular}{|c|c|c|c|c|c|c|c|c|c|c|c|}
\hline \multirow[b]{3}{*}{ 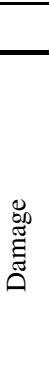 } & \multicolumn{11}{|c|}{ Steel Buildings } \\
\hline & \multicolumn{6}{|c|}{ Moment resisting frame direction } & \multicolumn{5}{|c|}{ Braced direction } \\
\hline & 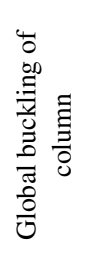 & 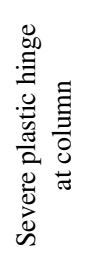 & 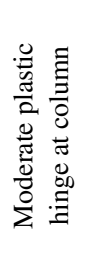 & 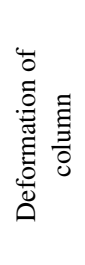 & 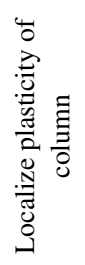 & 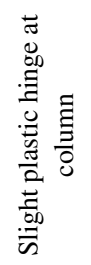 & 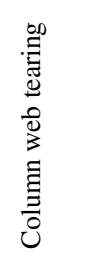 & 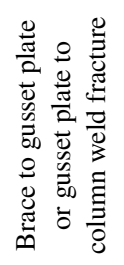 & 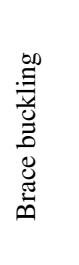 & 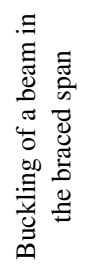 & 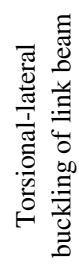 \\
\hline $\begin{array}{l}\frac{\overrightarrow{0}}{00} \\
\frac{0}{0} \\
\frac{10}{3}\end{array}$ & 10 & 8 & 6 & 6 & 4 & 2 & 10 & 10 & 6 & 2 & 2 \\
\hline 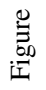 & - & 9.c & $9 . \mathrm{b}$ & 10 & 11 & 9.a & 14.e\&g & 14.d\&f & 14.a & 14.c & 14.h \\
\hline
\end{tabular}

All of the observed RC buildings' lateral load resisting system is the moment-resisting frame in both directions; So only one direction is considered in the proposed relation for RC buildings. Thus, Equation 5 is proposed to calculate the DI of each story.

$$
S D I=\frac{1}{M p d}\left(\sum_{i=1}^{11} \frac{N_{C_{i}}}{N_{C_{t}}} d i c_{i}+\sum_{i=1}^{11} \frac{N_{B_{j}}}{N_{B_{t}}} d i b_{j}+\sum_{i=1}^{5} \frac{N_{J_{k}}}{N_{J_{t}}} d i j_{k}\right)
$$

which $N_{C_{i}}$ represents the number of columns suffering from damage type $i$ in each story, dic $i$ is the weight assigned to damage type $i$ representing its intensity, $N_{C_{t}}$ represents the number of all columns in each story, $N_{B j}$ represents the number of beams suffering from damage type $j$ in each story, $d i b_{j}$ is the weight assigned to damage type $j, N_{B_{t}}$ represents the number of all beams in each story, $N_{J_{k}}$ represents the number of beam-column joints suffering from damage type $k$ in each story, $d i c_{k}$ is the weight assigned to damage type $k, N_{J_{t}}$ represents the number of all beamcolumn joints in each story.

In Equation 5, similar to Equation 3, to normalize the SDI to a number between 0 and 1, the final value is divided by Mpd coefficient which is 25 for RC buildings. The value is obtained as a summation of assigned weights to the most severe damage types in columns, beam-column joints, and beams (concrete core destruction). Table 2 shows the considered weights for different types of damages in RC buildings.

Table 2 Prevalent damages in RC buildings, the assigned weights to the damages, and sample figures 


\begin{tabular}{|c|c|c|c|c|c|c|c|c|c|c|}
\hline \multicolumn{11}{|c|}{ RC Structures } \\
\hline & \multicolumn{10}{|c|}{ Column } \\
\hline Damage & $\begin{array}{c}\text { Concrete } \\
\text { core } \\
\text { destruction }\end{array}$ & $\begin{array}{c}\text { Partial } \\
\text { crushing of } \\
\text { concrete } \\
\text { core }\end{array}$ & $\begin{array}{l}\text { Severe } \\
\text { crushing of } \\
\text { concrete } \\
\text { cover }\end{array}$ & $\begin{array}{l}\text { Partial } \\
\text { crushing of } \\
\text { concrete } \\
\text { cover }\end{array}$ & Spalling & $\begin{array}{l}\text { Shear } \\
\text { crack } \\
>1 \mathrm{~mm}\end{array}$ & $\begin{array}{l}\text { Shear } \\
\text { crack } \\
<1 \mathrm{~mm}\end{array}$ & $\begin{array}{l}\text { Vertical } \\
\text { crack }\end{array}$ & $\begin{array}{c}\text { Flexural } \\
\text { crack > } \\
1 \mathrm{~mm}\end{array}$ & $\begin{array}{c}\text { Flexural } \\
\text { crack } \\
<1 \mathrm{~mm}\end{array}$ \\
\hline Weight & 10 & 8 & 8 & 7 & 7 & 7 & 5 & 4 & 2 & 1 \\
\hline \multirow[t]{2}{*}{ Figure } & 17.h, i \& j & 17.g & $17 . \mathrm{g}$ & 17.f & 17.e & 17.c & - & 17.d & 17.a & - \\
\hline & \multicolumn{10}{|c|}{ Beam } \\
\hline Damage & $\begin{array}{c}\text { Concrete } \\
\text { core } \\
\text { destruction }\end{array}$ & $\begin{array}{l}\text { Partial } \\
\text { crushing of } \\
\text { concrete } \\
\text { core }\end{array}$ & $\begin{array}{c}\text { Severe } \\
\text { crushing of } \\
\text { concrete } \\
\text { cover }\end{array}$ & $\begin{array}{l}\text { Partial } \\
\text { crushing of } \\
\text { concrete } \\
\text { cover }\end{array}$ & Spalling & $\begin{array}{l}\text { Shear } \\
\text { crack > } \\
0.5 \mathrm{~mm}\end{array}$ & Shear & $\begin{array}{l}\mathrm{ck}<0.5 \\
\mathrm{n}\end{array}$ & $\begin{array}{l}\text { Flexural } \\
\text { crack }> \\
0.5 \mathrm{~mm}\end{array}$ & $\begin{array}{c}\text { Flexural } \\
\text { crack < } \\
0.5 \mathrm{~mm}\end{array}$ \\
\hline Weight & 5 & 4 & 4 & 3.5 & 3.5 & 3.5 & & & 1 & 0.5 \\
\hline \multirow[t]{2}{*}{ Figure } & - & - & - & - & 19.f & 19.c\&d & & & 19.a & - \\
\hline & \multicolumn{10}{|c|}{ Beam-column joint } \\
\hline Damage & \multicolumn{2}{|c|}{$\begin{array}{l}\text { Concrete core } \\
\text { destruction }\end{array}$} & \multicolumn{2}{|c|}{$\begin{array}{l}\text { Concrete cover crushing and } \\
\text { reinforcement exposure }\end{array}$} & \multicolumn{2}{|c|}{$\begin{array}{l}\text { Severe diagonal } \\
\text { crack }\end{array}$} & & $\begin{array}{l}\text { erate diagonal } \\
\text { crack }\end{array}$ & \multicolumn{2}{|c|}{ Hairline crack } \\
\hline Weight & \multicolumn{2}{|l|}{10} & \multicolumn{2}{|l|}{10} & \multicolumn{2}{|r|}{7} & & 5 & \multicolumn{2}{|r|}{3} \\
\hline Figure & \multicolumn{2}{|l|}{ 20.d } & \multicolumn{2}{|c|}{$20 . b \& c$} & \multicolumn{2}{|r|}{-} & \multicolumn{2}{|r|}{$20 . \mathrm{a}$} & \multicolumn{2}{|r|}{ - } \\
\hline
\end{tabular}

Similar to structural elements, according to Equation 6, a DI is proposed for each story's non-structural elements (walls and partitions).

$$
N S D I=\frac{1}{M p d}\left(\sum_{i=1}^{3} \frac{L_{W_{i}}}{L_{W_{t}}} \operatorname{diw}_{i}\right)
$$

which $L_{W_{i}}$ represents the length of walls (and partitions) suffering from damage type $i$ in each story, diw $w_{i}$ is the weight assigned to damage type $i, L_{w_{t}}$ represents the total length of walls in each story. In this equation, to normalize the non-structural damage index (NSDI) to a number between 0 and 1 , the final value same as the process defined for SDI should be divided by the maximum probable DI value for non-structural component in each story. This value for non-structural members is 10 . This value is obtained as the weight for the most severe damage (partial or complete collapse of a wall). Table 3 shows different weights assigned to different types of wall damages.

Table 3 Damages in walls and partitions, the assigned weights to the damages, and sample figures

\begin{tabular}{cccc}
\hline & \multicolumn{3}{c}{ Walls and partitions } \\
\hline Damage type & Complete or partial collapse of wall & Severe diagonal or sliding crack & Slight damage \\
Weight & 10 & 8 & 1 \\
Figure & $23 . \mathrm{d}$ & $23 . \mathrm{b} \mathrm{\&} \mathrm{c}$ & $23 . \mathrm{a}$ \\
\hline
\end{tabular}

Figure 29 shows the probability density function (PDF) and CDF of structural and non-structural damage indices of steel buildings (solid bars vs. hollow bars). According to Figure 29a, it is evident that in more than $50 \%$ of buildings, the SDI is less than 0.2. This means that these buildings experienced minor structural damages in their stories. Moreover, nearly $90 \%$ of buildings have a SDI of less than 0.6 . Buildings with a SDI greater than 0.8 have a very critical condition (for example, a residual drift of nearly $4 \%$ in the first story of a building with a SDI of 0.93 (Fig.30a)) in such a way that in order to be again serviceable, almost all of its columns and braces in the first story require to be strengthened or replaced. In general, the SDI of about 1 can be considered the collapse limit of steel buildings, and a building with a SDI greater than 1 can be considered a destroyed or highly damaged building that is not repairable. On the other hand, according to Figure 29b, in more than $20 \%$ of buildings, the NSDI is less than 0.2 , in nearly $60 \%$ of buildings is in the range of 0.2 and 0.6 , and approximately in $20 \%$ of buildings is greater than 0.6 . This means that several buildings that did not experience structural damage or suffered limited minor structural damages sustained 
relatively severe non-structural damages. Figure 30 shows the conditions of three steel buildings with different structural and non-structural damage indices.
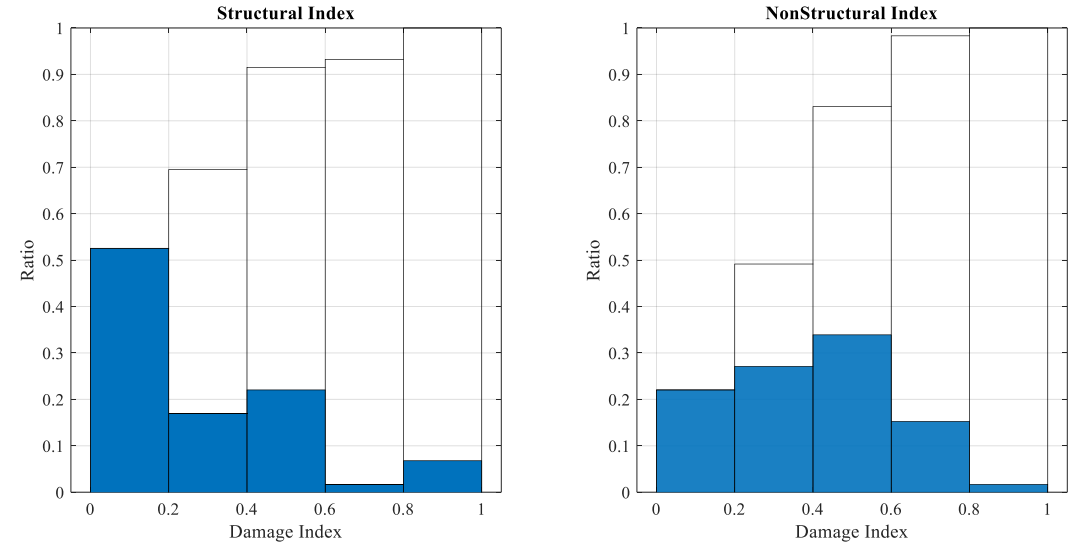

Fig. 29. PDF and CDF of streel buildings damage indices

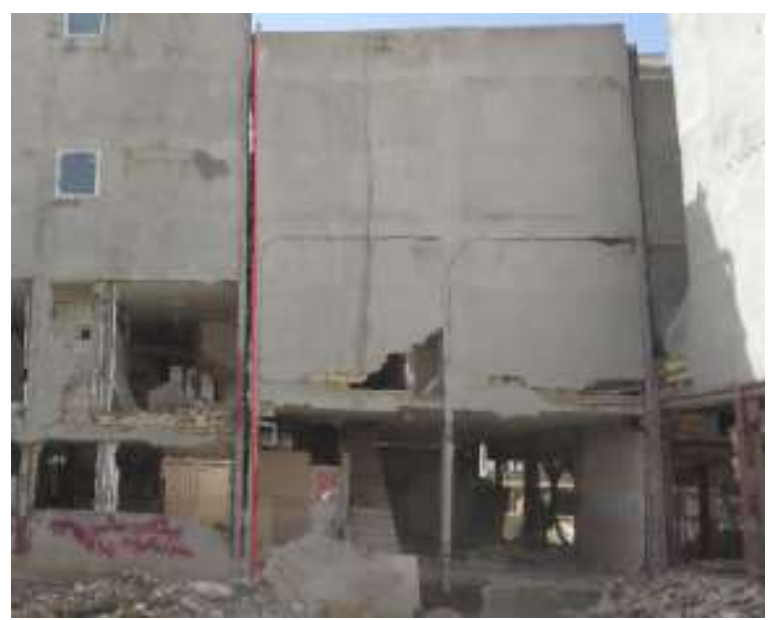

(A)

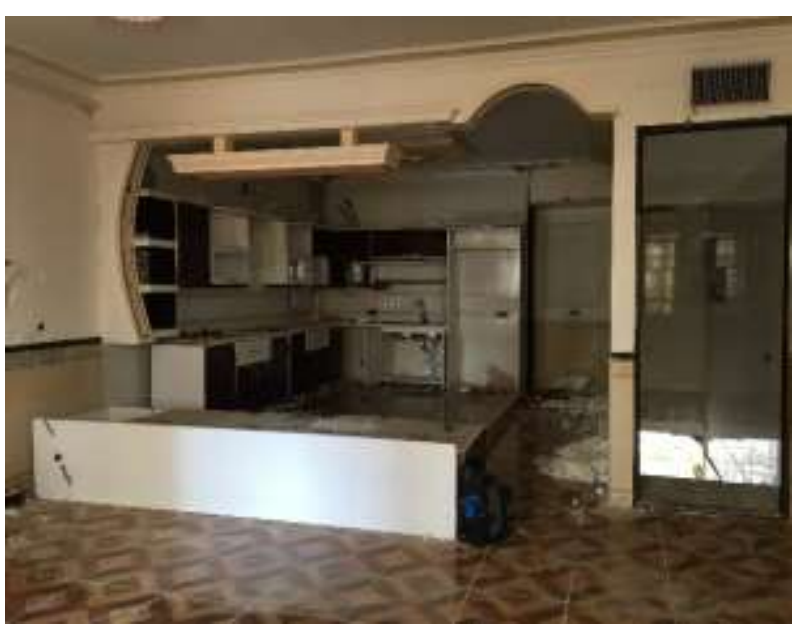

(B)

a. A steel building with the SDI $=0.93$ and NSDI $=1$. A) $4 \%$ residual drift in the first story. B) condition of the building in the second story

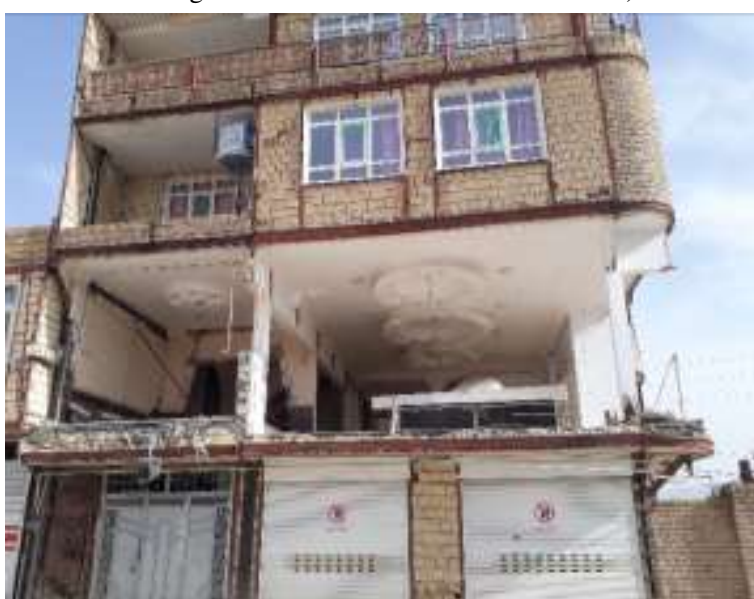

b. A building with SDI $=0.34$ and NSDI $=1$

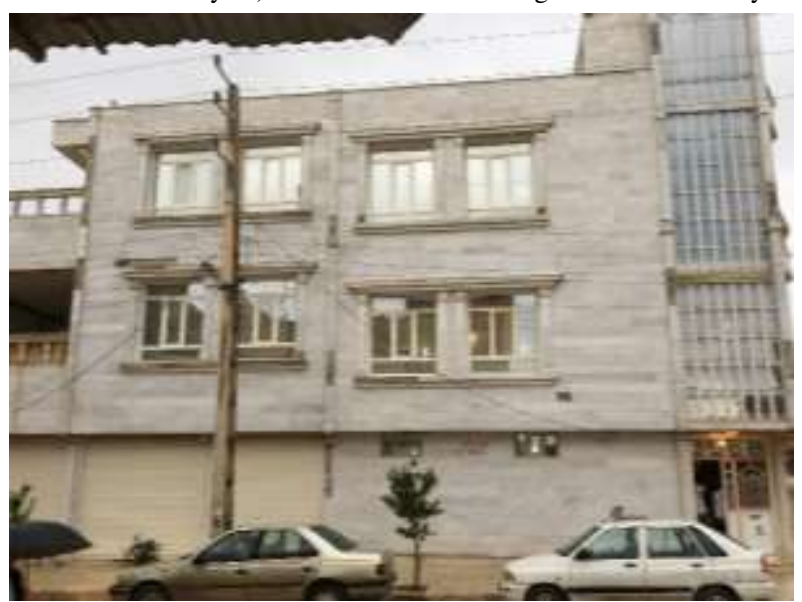

c. A building with SDI $=0$ and NSDI $=0.036$

Fig. 30. Steel buildings with different SDI and NSDI

Figure 31 shows the PDF and CDF of RC buildings' structural and non-structural damage indices (solid bars vs. hollow bars). According to Figure 31a, in more than $50 \%$ of RC buildings, the SDI is less than 0.2. It means that these 
buildings experienced minor structural damages in their stories. Furthermore, all buildings have structural damage indices less than 0.65 . The difference between the SDI of the most damaged steel and RC building is due to ignoring the damage to the beams in the proposed equation for steel buildings. As noted earlier, in the MRF direction of steel buildings, all beams remained intact, but in RC buildings, some beams experienced minor damages and for this reason these elements were taken into account in the proposed equation for RC buildings. According to Figure 31a, a low percentage (about 5\%) of RC buildings have a SDI between 0.5 and 0.6. These buildings have a very high level of damage in such a way that approximately a SDI between 0.5 and 0.65 in RC buildings can be considered corresponding to a DI between 0.85 and 1 in steel buildings. Lack of ductility and brittle behavior of RC members compared to steel members due to deficient details and concrete compressive strength weakness can be considered the main reasons for the non-resilience of RC buildings to higher damage indices before the collapse of the building. Therefore, the SDI approximately equal to 0.7 can be considered the limit before the buildings collapse. On the other hand, according to Figure $31 \mathrm{~b}$, approximately $55 \%$ of RC buildings have a NSDI greater than 0.5 , and in more than $15 \%$ of buildings this index is greater than 0.75 . Thus, it can be concluded that non-structural elements in RC buildings are more vulnerable than steel buildings. This may be due to the lower stiffness and, as a result, more displacement demand in RC buildings compared to the steel buildings. Figure 32 shows RC buildings with different structural and non-structural damage indices.
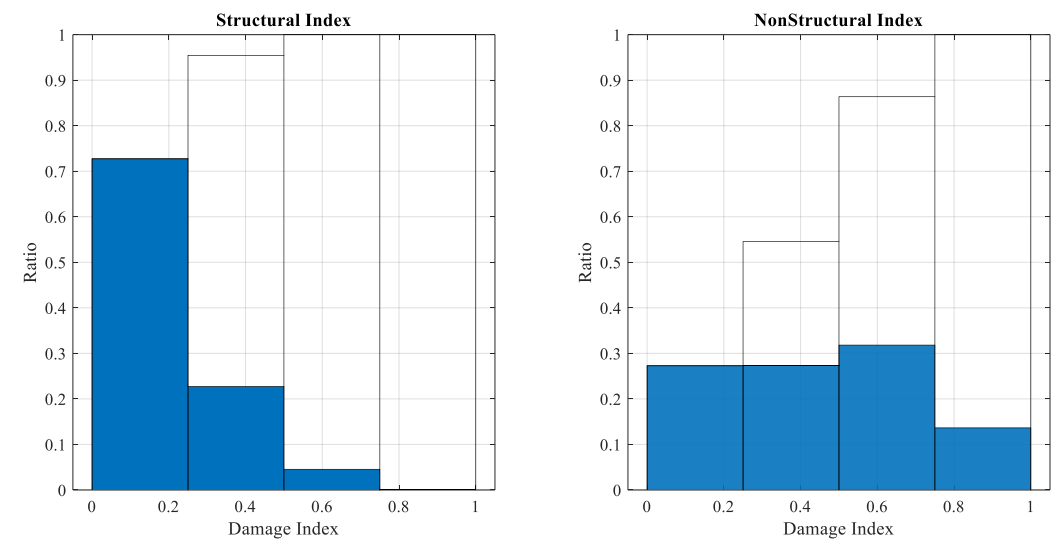

Fig. 31. PDF and CDF of RC buildings damage indices

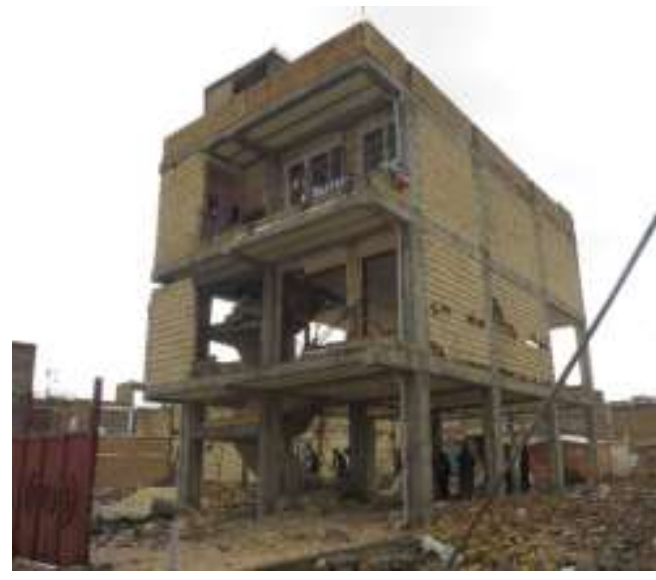

a. $\mathrm{RC}$ building with the $\mathrm{SDI}=0.35$ and $\mathrm{NSDI}=1$

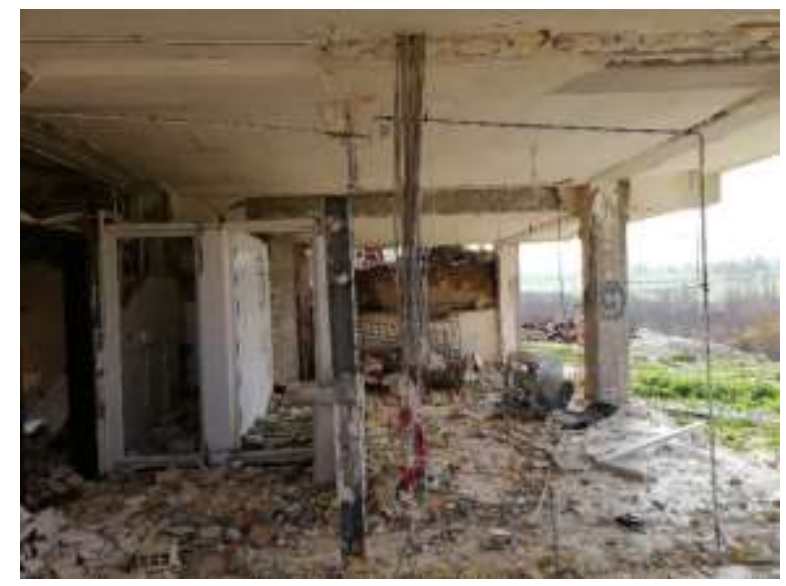

b. $\mathrm{RC}$ building with the SDI $=0.18$ and $\mathrm{NSDI}=1$

Fig. 32. RC buildings with different SDI and NSDI 


\section{Damage state (DS)}

As mentioned, in most studies and instructions such as HAZUS (1999), the classification of buildings in terms of their damages has been done qualitatively, and a detailed quantitative discussion about what percentage of structural elements suffered damage and how severely they were, has not been done. Presentation of quantitative criteria for damage can play an influential role in determining the amount of financial loss and the required funding allocated by governments for structural seismic retrofitting. Therefore, in this section, concerning the reported findings in section 3 and the structural damage indices introduced in section 5, buildings are classified based on the severity and extent of their damages. In fact, a quantitative DS is proposed. The purpose of this section is to provide a quick and accurate approach for the classification of buildings based on the severity and extent of observed damages during the visual inspection of them after a catastrophic event such as an earthquake.

For this purpose, based on the prevalent observed damages, using the statistic investigations and author's judgment, a correlation between the 5 DSs, damage extent and severity, and the introduced damage indices is shown in Tables 4 $\& 5$ for steel and RC buildings. Tables $4 \& 5$ cover the states ranging from buildings with minor damages (insignificant Damage state), which do not require retrofitting, to buildings in pre-collapse condition (extreme damage state). In the preparation of Tables $4 \& 5$, the amount and severity of the most prevalent observed generalizable damages are used to classify buildings. Usually, an earthquake-damaged building sustains various types of damages with different severity in stories; So, almost all of the damages are observable in a damaged building. The percentages presented in these tables are a good guide for the rapid post-earthquake assessment team by which they can provide a proper assessment of the building damage level by counting the number of damaged elements. Generally, the most critical observed damages play a pivotal role in classifying damaged buildings into different DSs. For instance, severe plastic hinges and global buckling of columns have the most influence on steel buildings classification, while there is a high probability that other damages such as moderate and slight plastic hinges are observed in the damaged building. In cases where global buckling of columns is not observed, residual drift caused by the formation of plastic hinges would significantly affect the building DS determination. For example, if a building has experienced about 3\% interstory residual drift and only $10 \%$ of its columns suffered from the severe plastic hinge, it would be classified as "high" according to Table 4 . Table 4 shows that residual interstory drift ratios equal to $3 \%$ and $1.5 \%$ (considering design and construction practice) can be considered the building collapse limit state for MRF and braced direction, respectively. Furthermore, concerning the percentage of each damage occurrence, the range of damage indices corresponding to different DSs is calculated using Equation 3. As shown in Table 4, in the DI of about 1, one can expect the collapse of steel buildings. This result completely follows the field observations; Those buildings with a DI of about 1 were destroyed and rebuilt after the earthquake. Table 5 shows the RC building classification based on the extent and severity of common frequent damages. With regard to the extent and distribution of damages observed in the elements of RC buildings, including beams, columns, and joints, and based on engineering judgment, the limits and percentages of different damages for different DSs are reported in Table 5.

Since the residual drift of RC buildings was variable and dispersed due to the severity and type of observed damages, it was impossible to determine the appropriate range for this parameter. According to Table 2, in addition to the columns, the most importance is given to the beam-column joints, especially for severe diagonal cracks, concrete cover, or core crushing and reinforcement exposure, but since these types of damages are more observable in the side and corner connections (Fig.20) and even in some cases due to the presence of neighboring buildings it was not possible to inspect them, a low percentage of beam-column joints (approximately 30\%) was investigated. Since the occurrence of damage to the central beam-column joints, which is not observable, is less probable and also because, in the proposed DI equation for RC buildings (Equation 5), beams have been considered (previously in section 3, it was mentioned), the calculated DI of reported RC buildings in this study, is not more than 0.6. An example of collapsed $\mathrm{RC}$ buildings due to the damages to beam-column joints is shown in Figure 33. This building collapsed due to the loss of shear strength in beam-column joints. Therefore, the collapse of this building indicates the damage indices greater than 0.6. Similarly, the damage indices greater than 0.6-0.7 were considered as the collapse limit in the previous studies conducted by Okada and Takai (2000) and Rossetto and Elnashai (2003) (tables of non-ductile RC momentresisting frames). 


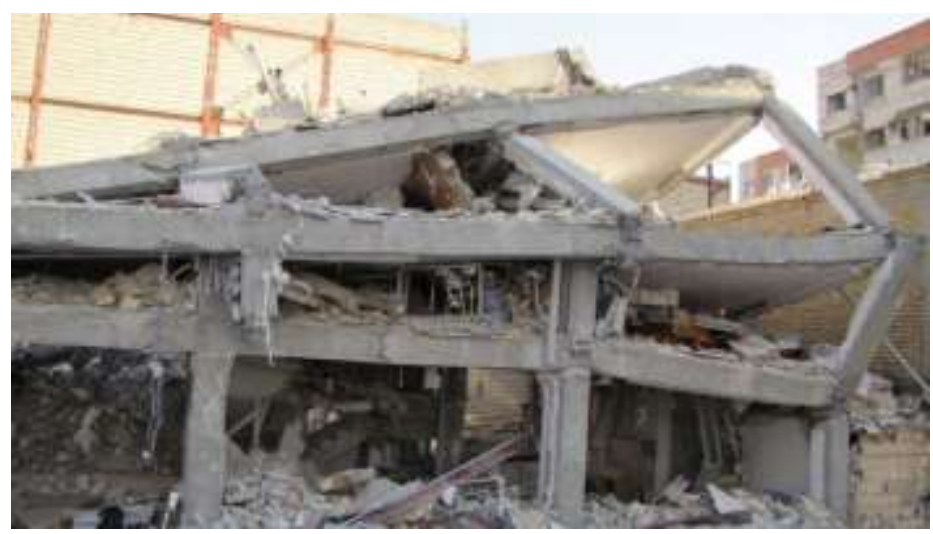

Fig. 33. A collapsed RC building due to failure in beam - column joints

Table 4 Damage state and damage index of steel buildings

\begin{tabular}{|c|c|c|c|c|c|c|c|c|c|c|}
\hline & \multicolumn{5}{|c|}{ Moment-resisting frame } & \multicolumn{4}{|c|}{ Braced frame } & \multirow[b]{2}{*}{$\begin{array}{l}\text { Damage } \\
\text { Index } \\
\text { (DI) }\end{array}$} \\
\hline $\begin{array}{l}\text { Damage } \\
\text { State (DS) }\end{array}$ & 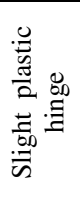 & 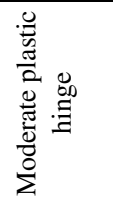 & 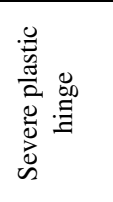 & 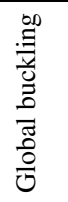 & 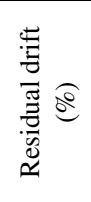 & 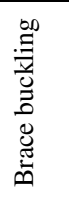 & 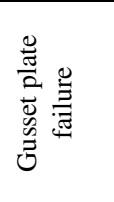 & 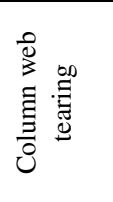 & 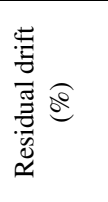 & \\
\hline Insignificant & $<40$ & - & - & - & 0 & - & - & - & 0 & $\mathrm{DI}<0.1$ \\
\hline Slight & $<20$ & $<30$ & - & - & $0<<1$ & $<40$ & $<20$ & - & $<0.4$ & $0.1<$ DI $<0.3$ \\
\hline Moderate & $<20$ & $30<<50$ & $<10$ & - & $1<<2$ & $<40$ & $<40$ & $<20$ & $0.4<<1$ & $0.3<$ DI $<0.6$ \\
\hline High & $<20$ & $20<<40$ & $10<<30$ & $<10$ & $2<<3$ & $40<$ & $40<<60$ & $20<<50$ & $1<<1.5$ & $0.6<$ DI $<0.9$ \\
\hline Extreme & - & $<40$ & $40<$ & $<10$ & $3-4<$ & $50<$ & $50<$ & $40<$ & $1.5<$ & $0.9<\mathrm{DI}<1$ \\
\hline
\end{tabular}


Table5 Damage state and damage index of RC buildings

\begin{tabular}{|c|c|c|c|c|c|c|c|c|c|c|c|c|c|c|c|}
\hline & \multicolumn{5}{|c|}{ Columns } & \multicolumn{5}{|c|}{ beams } & \multicolumn{4}{|c|}{ joints } & \multirow[b]{2}{*}{$\begin{array}{l}\text { Damage } \\
\text { Index } \\
\text { (DI) }\end{array}$} \\
\hline $\begin{array}{l}\text { Damage } \\
\text { State (DS) }\end{array}$ & $\begin{array}{l}\text { Flexural } \\
\text { crack }\end{array}$ & $\begin{array}{c}\text { Vertical } \\
\text { crack or } \\
\text { shear } \\
\text { crack } \\
<1 \mathrm{~mm}\end{array}$ & $\begin{array}{c}\text { Shear } \\
\text { crack> } \\
1 \mathrm{~mm} \text { or } \\
\text { cover } \\
\text { spalling }\end{array}$ & $\begin{array}{l}\text { Severe } \\
\text { spalling } \\
\text { of cover } \\
\text { or slight } \\
\text { core } \\
\text { crushing }\end{array}$ & $\begin{array}{l}\text { Extreme } \\
\text { or } \\
\text { complete } \\
\text { core } \\
\text { crushing }\end{array}$ & $\begin{array}{l}\text { Flexural } \\
\text { crack }\end{array}$ & $\begin{array}{c}\text { Shear } \\
\text { crack } \\
<0.5 \\
\mathrm{~mm}\end{array}$ & $\begin{array}{l}\text { Shear } \\
\text { crack> } \\
0.5 \mathrm{~mm} \\
\text { or cover } \\
\text { spalling }\end{array}$ & $\begin{array}{l}\text { Severe } \\
\text { spalling } \\
\text { of cover } \\
\text { or slight } \\
\text { core } \\
\text { crushing }\end{array}$ & $\begin{array}{l}\text { Extreme } \\
\text { or } \\
\text { complete } \\
\text { core } \\
\text { crushing }\end{array}$ & $\begin{array}{c}\text { Slight } \\
\text { hairline } \\
\text { and } \\
\text { diagonal } \\
\text { cracks }\end{array}$ & $\begin{array}{l}\text { Severe } \\
\text { diagonal } \\
\text { crack }\end{array}$ & $\begin{array}{c}\text { Extreme } \\
\text { diagonal } \\
\text { crack }\end{array}$ & $\begin{array}{l}\text { Cover } \\
\text { or core } \\
\text { crushing } \\
\text { and } \\
\text { exposed } \\
\text { rebars }\end{array}$ & \\
\hline Insignificant & $<5$ & - & - & - & - & $<5$ & - & - & - & - & - & - & - & - & $<0.02$ \\
\hline Slight & $5<<20$ & $<15$ & $<15$ & - & - & $<10$ & $<10$ & - & - & - & - & - & - & - & $0.02<<0.1$ \\
\hline Moderate & $5<<30$ & $5<<20$ & $10<<25$ & $<15$ & - & $5<<15$ & $5<<15$ & $<10$ & - & - & $<15$ & $<10$ & - & - & $0.1<<0.25$ \\
\hline Heavy & $25<<50$ & $5<<20$ & $20<<45$ & $5<<20$ & - & $5<<15$ & $10<<25$ & $10<<25$ & - & - & $<20$ & $<30$ & $<10$ & $<10$ & $0.25<<0.4$ \\
\hline Extreme & $<25$ & $<15$ & $10<<30$ & $15<<25$ & $<10$ & $15<<30$ & $10<<25$ & $10<<25$ & $<10$ & $<10$ & $10<<30$ & $10<<30$ & $<15$ & $<15$ & $0.4<<0.6$ \\
\hline
\end{tabular}

*The numbers in the table are in percent and belong to each story. 


\section{Comparing and validating with other reported damage states and indices}

To discuss the proposed damage states and damage indices more comprehensively, this study's results are presented corresponding to the classifications performed in other research and instructions (Tables $6 \& 7$ ). The quantification of damage indices in the literature has been primarily based on analytical models and experimental observations. Using behavioral characteristics such as stiffness, deformation (ductility), and energy are among the most important of these methods. The use of empirical values based on post-earthquake damage observations has been less reported in the literature. Accordingly, the qualitative and quantitative comparison of damage cases shows how close the quantitative indices of literature can be near reality. Tables $6 \& 7$ represent a comparison between different damage states and indices defined in the literature, instructions, and the current study for RC and steel buildings, respectively. This comparison is acquired using the severity and extent of damages explained in each of the mentioned reports. As can be seen, there is a good correspondence (both qualitative and quantitative) between the damage states and indices defined by field investigations in this study and other reports. However, it should be noted that the basis of the proposed damage indices in this study is different from the numerical approach (Rossetto and Elnashai 2003) presented in Table 6 . The correlation between the defined ranges for damage indices in this study and those proposed by other researchers demonstrates that the DI can be calculated based on numerical studies. However, the real distribution of damages can be determined based on what is defined in empirical and field research such as the current study. This can be a reasonable basis for future uses, such as issues related to resilience, recovery time, and cost of retrofitting and reconstruction.

Table 6 Comparing the proposed damage index and damage state with other research for RC buildings

\begin{tabular}{|c|c|c|c|c|c|c|c|c|c|}
\hline \multicolumn{10}{|c|}{ RC Buildings } \\
\hline \multicolumn{2}{|c|}{ Proposed in current study } & $\begin{array}{l}\text { Sinha and } \\
\text { Shiradhonkar } \\
(2012)\end{array}$ & $\begin{array}{l}\text { Grünthal } \\
\text { (1998) }\end{array}$ & $\begin{array}{c}\text { Okada } \\
\text { and Takai } \\
(2000)\end{array}$ & \multicolumn{2}{|c|}{$\begin{array}{c}\text { Rossetto and } \\
\text { Elnashai (2003) }\end{array}$} & $\begin{array}{l}\text { Anagnostopoulos } \\
\text { et al. (2004) }\end{array}$ & $\begin{array}{l}\text { Baggio } \\
\text { et al. } \\
(2007)\end{array}$ & $\begin{array}{c}\text { HAZUS } \\
(1999)\end{array}$ \\
\hline DS & DI & DS & $\overline{\mathrm{DS}}$ & DI & DS & $\overline{\mathrm{DI}}$ & $\overline{\mathrm{DS}}$ & DS & $\overline{\mathrm{DS}}$ \\
\hline None & 0 & None & None & 0 & None & 0 & & $\begin{array}{l}\text { D0: No } \\
\text { damage }\end{array}$ & None \\
\hline Insignificant & $<0.02$ & S1-Slight & $\begin{array}{c}\text { Grade 1: } \\
\text { Negligible to } \\
\text { slight } \\
\text { damage }\end{array}$ & $0<<0.2$ & Slight & $\begin{array}{l}10 \\
20\end{array}$ & None & $\begin{array}{c}\text { D1: } \\
\text { Slight }\end{array}$ & Slight \\
\hline Slight & $0.02<<0.1$ & S2-Light & $\begin{array}{c}\text { Grade 2: } \\
\text { Moderate } \\
\text { damage }\end{array}$ & $0.2<<0.4$ & Light & $\begin{array}{l}30 \\
40\end{array}$ & Slight & damage & damage \\
\hline Moderate & $0.1<<0.25$ & S3-Moderate & $\begin{array}{l}\text { Grade 3: } \\
\text { Substantial } \\
\text { to heavy } \\
\text { damage }\end{array}$ & $0.4<<0.6$ & Moderate & 60 & $\begin{array}{l}\text { Moderate - } \\
\text { Heavy }\end{array}$ & $\begin{array}{l}\text { D2-D3: } \\
\text { Medium } \\
\text { to } \\
\text { severe } \\
\text { damage }\end{array}$ & $\begin{array}{c}\text { Moderate } \\
\text { structural } \\
\text { damage } \\
\text { Extensive }\end{array}$ \\
\hline Extreme & $0.4<<0.6$ & S4-Extensive & Grade 3 or 4 & $0.6<<0.7$ & & 70 & & & damage \\
\hline Collapse & $0.6<<1$ & S5-Collapse & $\begin{array}{l}\text { Grade } 4: \\
\text { Very heavy } \\
\text { damage } \\
\text { Grade 5: } \\
\text { Destruction }\end{array}$ & $0.7<<1$ & $\begin{array}{c}\text { Extensive } \\
\text { Partial } \\
\text { Collapse }\end{array}$ & $\begin{array}{l}90 \\
100\end{array}$ & Severe - Total & $\begin{array}{l}\text { D4-D5: } \\
\text { Very } \\
\text { heavy } \\
\text { damage }\end{array}$ & $\begin{array}{c}\text { Complete } \\
\text { structural } \\
\text { damage }\end{array}$ \\
\hline
\end{tabular}

Table 7 Comparing the proposed damage index and damage state with other research for steel buildings

\begin{tabular}{|c|c|c|c|}
\hline \multicolumn{4}{|c|}{ Steel buildings } \\
\hline \multicolumn{2}{|c|}{ Proposed in current study } & Anagnostopoulos et al. (2004) & HAZUS (1999) \\
\hline DS & DI & DS & DS \\
\hline Insignificant & $<0.1$ & None - Slight & Slight structural damage \\
\hline Moderate & $0.3<<0.6$ & & Moderate structural damage \\
\hline High & $0.6<<0.9$ & Moderate - Heavy & Fytencine ctructural domo \\
\hline Extreme & $0.9<<1$ & Severe - Total & Extensive structural damage \\
\hline Collapse & $1<$ & Severe - Total & Complete structural damage \\
\hline
\end{tabular}




\section{Developing seismic vulnerability curves}

The developed vulnerability curves of buildings using previous earthquakes data can be used in seismic risk assessment and future loss mitigation planning. This section explains the developing vulnerability curves using the proposed damage index. For this purpose, firstly, the intensity measure of ground motion beneath each building should be calculated. Then, regarding the amount of occurred damages to each building, which is estimated using the proposed damage index, vulnerability curves are developed for each type of building.

In this research, due to the limited number of investigated buildings in each type (RC buildings with moment-resisting frame, and steel buildings with concentrically braced frame or moment-resisting frame as a lateral load resisting system) as well as high accuracy in damage assessment of buildings, the direct approach is used to develop the vulnerability curves (Rossetto et al. 2014). Firstly, the soil condition beneath each building is described, then, using ground motion prediction equation (GMPE) and corresponding the empirical period of a given building, the spectral acceleration for that building is calculated. Finally, the vulnerability curve of each type of building is developed by fitting the best curve to the processed data.

\subsection{Soil properties}

Soil properties are one of the most critical parameters that affect the spectral acceleration beneath buildings. Figure 34 shows the distribution of damaged buildings in Sarpol-e Zahab. Several studies have been conducted on the soil properties of Sarpol-e Zahab city. In one of these studies, 18 boreholes were drilled in 5 districts of the city where had been seriously damaged during the earthquake to determine seismic properties of soil such as shear wave velocity for different soil layers. Most of the 81 investigated buildings in this research (shown by blue squares Figure 34) are near the abovementioned boreholes. In order to improve the accuracy of the results and determine the shear wave velocity in the whole city, the results of other studies (Ashayeri et al. 2019; Ashayeri et al. 2020; Ashayeri et al. 2021; Moosavi et al. 2019; Zafarani et al. 2020) in conjunction with the mentioned experiments are used. In Figure 34, the locations of these field tests are depicted by triangles, and the shown values are the average velocity of shear waves in the top $30 \mathrm{~m}$ of soil layers $\left(V_{S 30}\right)$.

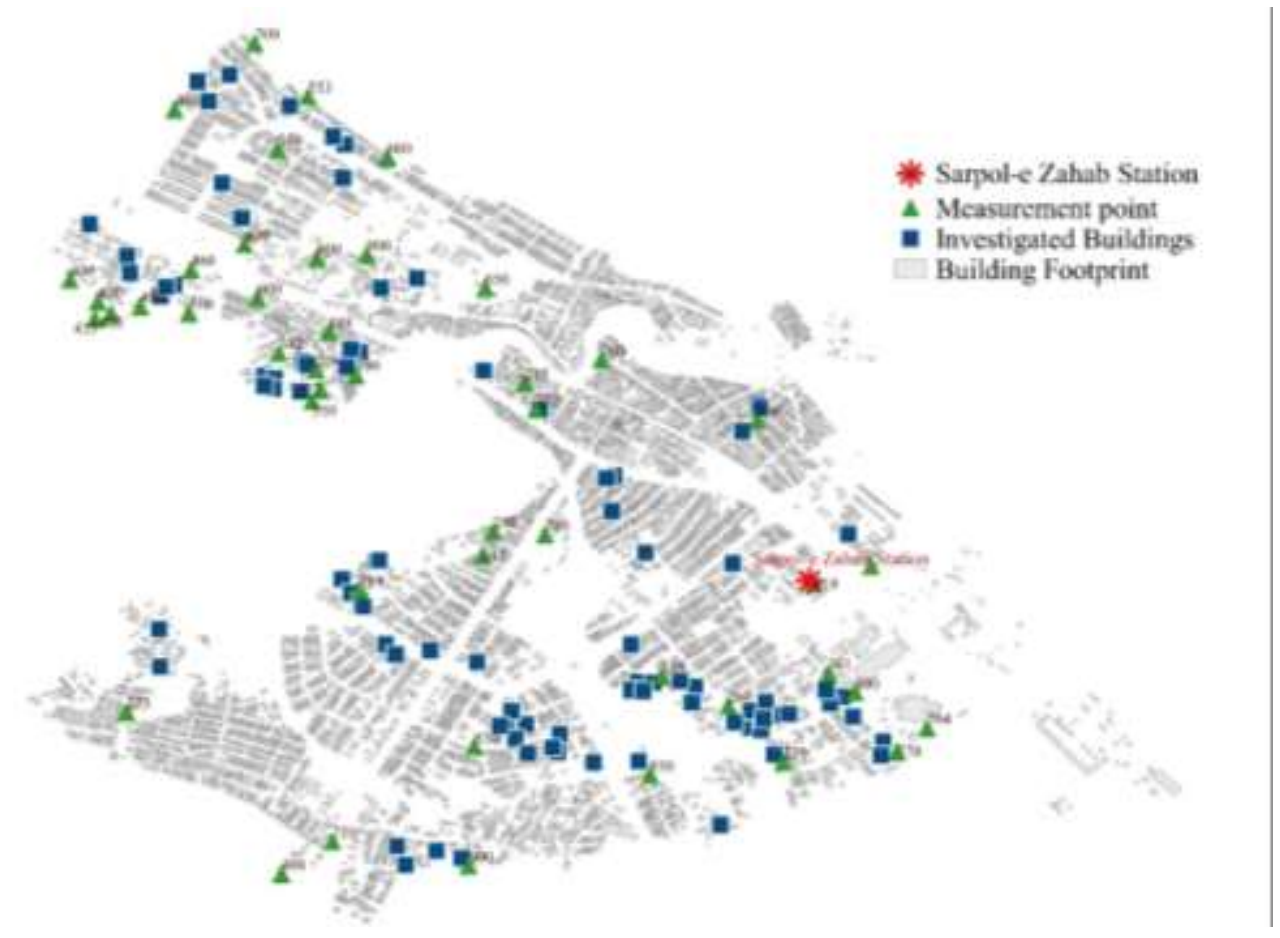

Fig. 34. Locations of investigated buildings and boreholes 


\subsection{Calculation of spectral acceleration}

There are different approaches to determine the spectral acceleration beneath buildings. One of these approaches is based on ground motion prediction equations (GMPEs) which determines the spectral acceleration with regard to the fault property and source-to-site distance. To complete this method, using spatial correlation relationships and concerning the recorded results by surrounding accelerogram stations, the spectral acceleration of bedrock is modified. Afterward, the spectral acceleration beneath a given building is calculated using soil amplification factors in GMPE relationships (Park et al. 2007; Miano et al. 2020). In the Sarpol-e Zahab earthquake, there are two significant points that can be helpful to simplify the method of calculating the spectral acceleration. Firstly, Sarpol-e Zahab accelerogram station is approximately located in the middle of the city. According to the borehole tests, $V_{S 30}$ beneath the accelerogram station is $619 \mathrm{~m} / \mathrm{s}$, as a result, the recorded spectral acceleration is approximately similar to the spectral acceleration at bedrock. Secondly, the maximum distance between the investigated buildings and the accelerogram station is $2.6 \mathrm{~km}$, so it can be supposed that the spectral acceleration on the bedrock is similar for all buildings, and the soil parameters beneath buildings, are the only source of difference of spectral acceleration beneath buildings. Thus, calculations for determining the spectral acceleration on bedrock through GMPE and using correlation relationships are approximately equal to the recorded spectral acceleration on bedrock beneath the accelerogram station. Consequently, spectral acceleration of bedrock beneath the accelerogram station is calculated using soil amplification factors in GMPE relationships, then considering soil properties beneath each building, soil factor for each period is calculated and finally multiplied in the spectral acceleration of bedrock.

In this research, the proposed relation in Boore et al. (2014) is used as a suitable GMPE for amplification factor calculation. Considering the nonlinear effects of soil in addition to its linear effects with respect to $V_{S 30}$ is the reason for this choice. In this method, the prediction equation for peak ground acceleration and velocity (PGA, PGV) as well as $5 \%$ damped pseudo-spectral acceleration (PSA) are as follows

$$
\ln Y=F_{E}(\mathbf{M} . \text { mech })+F_{P}\left(R_{J B} \text {. M.region }\right)+F_{S}\left(V_{S 30} \cdot R_{J B} \text {. M.region. } z_{1}\right)+\varepsilon_{n} \sigma\left(\mathbf{M} \cdot R_{J B} \cdot V_{S 30}\right)
$$

where $\ln Y$ represents the natural logarithm of a ground motion IM (PGA, PGV, or PSA); $F_{E}, F_{P}$, and $F_{S}$ represent functions for source ("E" for "event"), path ("P"), and site ("S") effects, respectively; $\varepsilon_{n}$ is the fractional number of standard deviations of a single predicted value of $\ln Y$ away from the mean; and $\sigma$ is the total standard deviation of the model. The parameter that is very important in this research is $F_{S}$ or soil effect, which is calculated as follows

$$
F_{S}\left(V_{S 30} \cdot R_{J B} \text {. M. region. } z_{1}\right)=\ln \left(F_{\text {lin }}\right)+\ln \left(F_{n l}\right)+F_{\delta z_{1}}\left(\delta z_{1}\right)
$$

where $F_{\text {lin }}$ represents the linear component of site amplification, $F_{n l}$ represents the nonlinear component of site amplification, and $F_{\delta z_{1}}$ represents the effects of basin depth.

Figure 35 shows the recorded spectral acceleration in the Sarpol-e Zahab station in the north-south direction compared to the calculated spectral acceleration on bedrock and one of the steel buildings in the moment-resisting frame direction. For this building $V_{S 30}=251 \mathrm{~m} / \mathrm{s}$; hence as shown in Figure 35, the soil amplification factor is high for greater periods. 


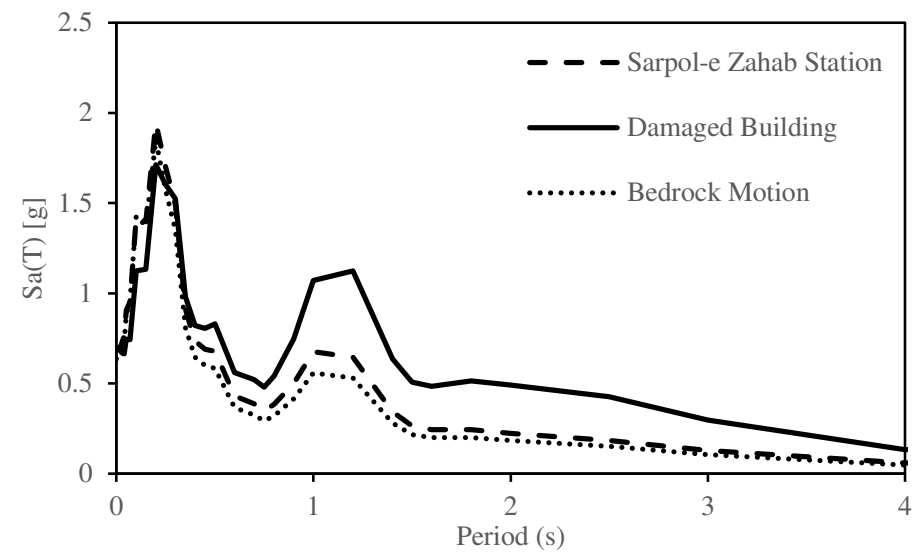

Fig. 35. Comparison between the spectral acceleration in Sarpol-e Zahab station, bedrock, and one of the investigated buildings

\subsection{Vulnerability curves}

As mentioned previously, few vulnerability curves have been developed in Iran, mostly based on Mercalli intensity and PGA as an intensity measure. Recently, Kohrangi et al. (2021) numerically have developed vulnerability curves using spectral acceleration at fundamental periods of intact buildings, which is different for damaged buildings. It is worth noting that Kohrangi et al. (2021), to develop vulnerability curves, fragility curves of different DSs (e.g., slight, moderate, etc.) are calculated. Then vulnerability curves are developed concerning the relationship between DS and building damage (consequence function).

In the current research, one of the advantages of using quantitative damage indices instead of qualitative is that it makes direct vulnerability curves calculation and development possible because of the large number of recorded damages and not limiting it to a few specific values.

In the first step, according to the proposed empirical relations in BHRC (2015) (Table 8), the periods of 3 different building types are calculated. It should be noted that Khanmohammadi et al. (2021), by conducting ambient vibration tests, have determined fundamental periods of some of the investigated buildings in the current research. However, to obtain comprehensive results from this method, it is preferred to use the commonly proposed relations of codes to calculate the spectral acceleration of each building in each direction.

Table 8 Empirical relations to calculate the fundamental periods of different types of buildings (BHRC 2015)

\begin{tabular}{ccc}
\hline Construction & Lateral Load Resisting System & Empirical Relation (T) \\
\hline \multirow{2}{*}{ Steel } & Moment Resisting Frame (MRF) & $0.08 H^{0.75}$ \\
& Concentric Braced (X-Braced) Frame & $0.05 H^{0.75}$ \\
RC & Moment Resisting Frame (MRF) & $0.05 H^{0.9}$ \\
\hline
\end{tabular}

${ }^{*} \mathrm{H}$ is in meters

After calculating the fundamental period in each direction, concidering the recorded spectral acceleration in both north-south and east-west directions in Sarpol-e Zahab station, spectral acceleration of buildings in each direction is calculated using the described method in the previous section. Afterward, points belonging to the spectral acceleration at fundamental periods of buildings and structural damage indices are plotted, as shown by blue curves in Figure 36. Finally, the vulnerability curve is fitted using a generalized linear regression model. It is worth noting some points about Figure 36: 
- For steel buildings, the vulnerability curve is developed separately for moment-resisting frame direction and concentrically braced direction, while there is only one vulnerability curve in RC buildings. This is due to the existence of two different lateral load resisting systems in steel buildings which leads to different fundamental periods for each direction. Thus, with regard to the formulation of the proposed damage indices, which makes it possible to calculate the amount of damage in each direction separately, two vulnerability curves are developed for steel buildings. On the other hand, due to the use of moment resisting frame as a lateral load resisting system in both directions of RC buildings, and as a result, equal fundamental periods for both directions, one vulnerability curve is developed for RC buildings.

- In order to have an appropriate result for typical RC buildings, a number of RC buildings that have unusual conditions in their construction, first-story height, and concrete compression strength, which cannot be in the same type as other buildings, are removed from the vulnerability curve development process.

- Classifying buildings with different characteristics (such as height) into one type is one of the advantages of using an intensity measure based on the spectral acceleration at fundamental period of buildings. However, differences in the quality of construction and the used design codes, which are functions of buildings age, should be considered as another taxonomy in this method. Another advantage of this method is increasing a range that the intensity measure in vulnerability curves is valid. While, if another intensity measure such as PGA were used, because of low distances between buildings and, as a result, low differences of PGA for different buildings, a significantly limited range of vulnerability curves would be valid.

- Drawing a Comparison between the vulnerability curves of Figure 36 shows that steel buildings in the Xbraced frame direction can withstand greater spectral accelerations. Also, steel buildings in the MRF direction are more susceptible than RC MRFs. However, it should be considered that the range of fundamental periods for steel MRFs is between $0.34 \mathrm{~s}$ and $0.61 \mathrm{~s}$, which is greater than X-braced frames (between $0.21 \mathrm{~s}$ and $0.33 \mathrm{~s}$ ), and in addition, according to the previous explanations, the maximum value of DI for investigated steel buildings is greater than RC buildings.

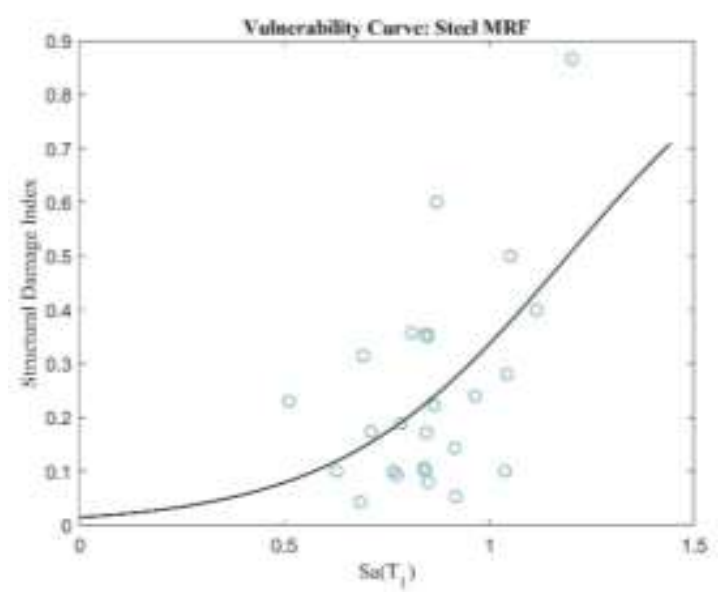

a. Steel buildings in moment resisting frame direction

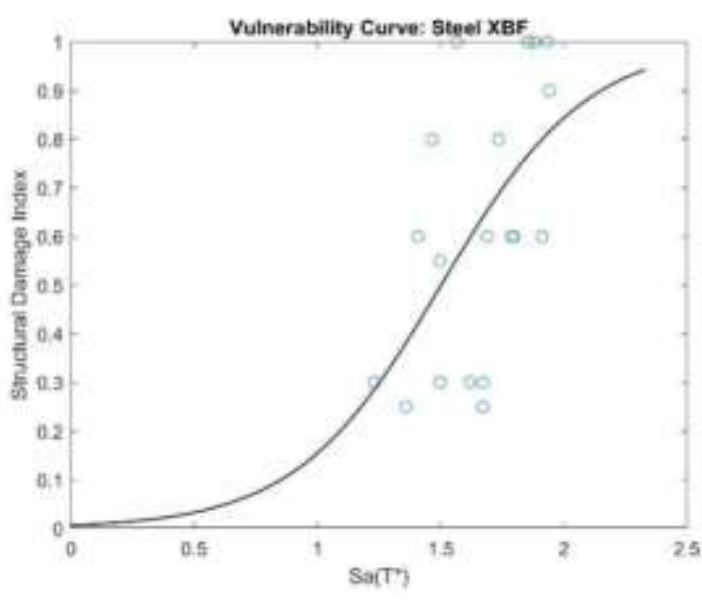

b. Steel buildings in concentric braced frame direction 


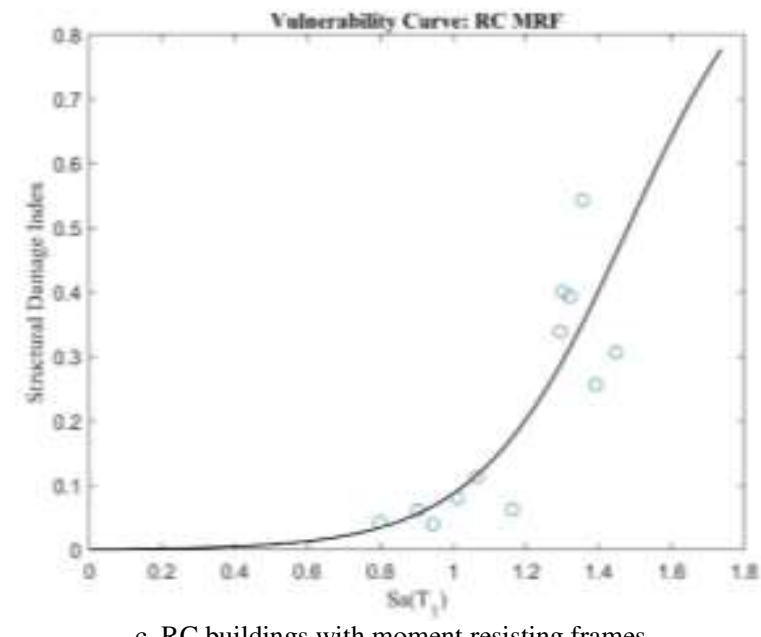

c. RC buildings with moment resisting frames

Fig. 36. Vulnerability curves for structural damages.

* $\mathrm{T}^{*}$ is fundamental periods of buildings calculated from code's empirical relations

In the end, the vulnerability curve of non-structural damages for all steel and RC buildings is shown in Figure 37 . The important point in developing the vulnerability curve of this figure is the use of the geometric mean of buildings' spectral accelerations in both directions. This is because the non-structural damage cannot be considered separately for each direction; hence, a combination effect of both directions is used as a suitable intensity measure in developing a non-structural vulnerability curve. A large scatter in the results of Figure 37 can be attributed to the several factors affecting the susceptibility of non-structural elements such as out-of-plane restraint of non-structural elements, quality of used materials, and construction practice.

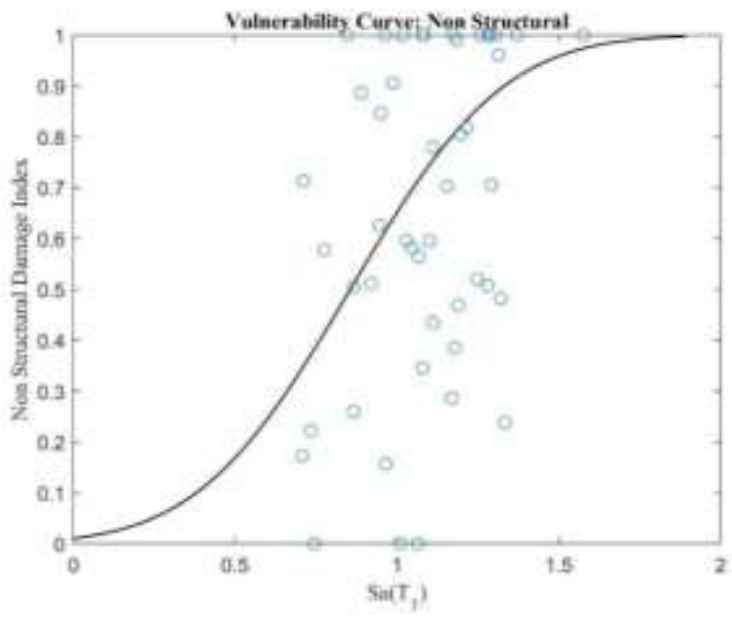

Fig. 37. Vulnerability curve for non-structural damages.

With regard to the use of generalized linear regression model along with the binomial distribution and logit link function to fit curves on data, equations between the damage indices and intensity measure which represents fitted curves of Figures $36 \& 37$ are as follows

$$
D I=\frac{e^{\left(b_{1}+b_{2} \times I M\right)}}{1+e^{\left(b_{1}+b_{2} \times I M\right)}}
$$


where $D I$ represents the proposed damage indices and $I M$ represents the spectral acceleration at the fundamental periods of buildings in terms of gravitational acceleration (g). Also, $b_{1}$ and $b_{2}$ are constant values which vary for different types of buildings. Table 9 shows values of $b_{1}$ and $b_{2}$ for different types of buildings.

Table 9 values of $b_{1}$ and $b_{2}$ for different types of buildings

\begin{tabular}{cccc}
\hline Construction & Lateral Load Resisting System & $b_{1}$ & $b_{2}$ \\
\hline \multirow{2}{*}{ Steel } & Moment Resisting Frame (MRF) & -4.2312 & 3.5516 \\
& Concentric Braced (X-Braced) Frame & -5.0821 & 3.3830 \\
RC & Moment Resisting Frame (MRF) & -7.2278 & 4.8796 \\
\multirow{2}{*}{ Non-structural damage } & -2.3043 & 2.6922 \\
\hline
\end{tabular}

\section{Conclusion}

A comprehensive visual inspection of different damaged structural systems was performed. A correlation between structural responses like residual drift and structural and non-structural damages is demonstrated through statistical and science-based analysis. Based on observations, for conventional RC and steel structural systems, different possible damage categories in both structural and non-structural elements are identified. Each system's damage category is quantified, and a quantitative-qualitative correlation between element-level damages and overall structural performance is introduced. The proposed damage indices and damage states were calibrated with field observations. Also, a comprehensive comparison between the suggested damage indices and damage states in previous studies and the proposed ones in this study is conducted and demonstrated that the results of this research are precise and valid.

In the recent study, in addition to establishing a relationship between structural and non-structural damages, a damage index was proposed in an effort to quantify the amount of actual damages. This index can be very useful in repairing, retrofitting, and insurance industry cost estimation.

In the last section, vulnerability curves of 3 types of buildings (RC buildings with moment-resisting frames, steel buildings with moment-resisting frames, and steel buildings with concentrically braced frames) are developed using the proposed damage indices and an intensity measure which is based on the spectral acceleration at fundamental periods of buildings. Although results are scattered, they are more valid and valuable than other vulnerability curves obtained from numerical or experimental tests because they are genuine and based on field observations.

This information could play a crucial role in a quick, reliable, and realistic earthquake assessment. These qualitative and quantitative criteria can be useful guides due to the lack of similar field studies on damaged buildings under severe earthquakes.

\section{References}

ACI 318-14 (2014) Building Code Requirements for Structural Concrete and Commentary and commentary, American Concrete Institute.

Anagnostopoulos S, Moretti M, Panoutsopoulou M, Panagiotopoulou D, Thoma T (2004) Post earthquake damage and usability assessment of buildings: further development and applications. Final report.

Ashayeri I, Biglari M, Sadr A, Haghshenas E (2019) Importance of revisiting (Vs) 30 site class index, Sarpol-e-zahab $\mathrm{Mw}=7.3$ earthquake. In Proceedings, 7th International Conference on Earthquake Geotechnical Engineering.

Ashayeri I, Sadr A, Biglari M, Haghshenas E (2020) Comprehensive ambient noise analyses for seismic microzonation of sarpol-e-zahab after the Mw 7.3 2017 Iran earthquake. Engineering Geology, 272, 105636. https://doi.org/10.1016/j.enggeo.2020.105636. 
Ashayeri I, Memari M A, Haghshenas E (2021) Seismic microzonation of Sarpol-e-zahab after Mw 7.32017 Iran earthquake: 1D-equivalent linear approach. Bulletin of Earthquake Engineering, 19(2), 605-622. https://doi.org/10.1007/s10518-020-00999-6.

Baggio C, Bernardini A, Colozza R et al (2007) Field manual for post-earthquake damage and safety assessment and short term countermeasures (AeDES). European Commission-Joint Research Centre-Institute for the Protection and Security of the Citizen, EUR, 22868.

Behboodi S, Bitaraf M, Nafisifard M (2021) Prevention of low-cycle fatigue damage using adaptive control approach and magnetorheological dampers. Structures, 33, 554-566. https://doi.org/10.1016/J.ISTRUC.2021.04.085.

BHRC (2015) Iranian code of practice for seismic resistant design of buildings, standard No. 2800, fourth edition, Building and Housing Research Center, Tehran, Iran.

Biglari M, Formisano A (2020) Damage probability matrices and empirical fragility curves from damage data on masonry buildings after Sarpol-e-zahab and Bam Earthquakes of Iran. Frontiers in built environment, 6, 2. https://doi.org/10.3389/fbuil.2020.00002.

Biglari M, Formisano A, Hashemi B H (2021) Empirical fragility curves of engineered steel and RC residential buildings after Mw 7.3 2017 Sarpol-e-zahab earthquake. Bulletin of Earthquake Engineering, 19(6), 2671-2689. https://doi.org/10.1007/s10518-021-01090-4.

Boore D M, Stewart J P, Seyhan E, Atkinson G M (2014) NGA-West2 equations for predicting PGA, PGV, and 5\% damped PSA for shallow crustal earthquakes. Earthquake Spectra, 30(3), 1057-1085. https://doi.org/10.1193/070113EQS184M.

Bruneau M, Eng P, Uang C M, Rafael Sabelli S E (2011) Ductile design of steel structures. McGraw-Hill Education.

Brzev S, Pandey B, Maharjan D K, Ventura C (2017) Seismic vulnerability assessment of low-rise reinforced concrete buildings affected by the 2015 Gorkha, Nepal, earthquake. Earthquake Spectra, 33(1_suppl), 275-298. https://doi.org/10.1193/120116eqs218m.

Dai K, Wang J, Li B, Hong H P (2017) Use of residual drift for post-earthquake damage assessment of RC buildings. Engineering Structures, 147, 242-255. https://doi.org/10.1016/j.engstruct.2017.06.001.

D'ayala D, Meslem A, Vamvastikos D, Porter K, Rossetto T, Crowley H, Silva V (2014) Guidelines for analytical vulnerability assessment of low/mid-rise Buildings-Methodology. Vulnerability Global Component project. https://doi.org/10.13117/GEM.VULN--MOD.TR2014.12.

DiPasquale E, Cakmak A S (1988) Identification of the serviceability limit state and detection of seismic structural damage. New York, NY, USA: National Center for Earthquake Engineering Research.

FEMA356 (2000) Prestandard and Commentary for the Seismic Rehabilitation of Buildings, Federal Emergency Management Agency (FEMA), Washington, DC, USA.

FEMA P-58-1 (2018) Seismic Performance Assessment of Buildings, Volume 1 - Methodology, Second Edition, Federal Emergency Management Agency (FEMA), Washington, DC, USA.

Ghobarah A, Abou-Elfath H, Biddah A (1999) Response-based damage assessment of structures. Earthquake engineering \& structural dynamics, 28(1), 79-104. https://doi.org/10.1002/(SICI)10969845(199901)28:1\%3C79::AID-EQE805\%3E3.0.CO;2-J

Ghobarah A (2004) On drift limits associated with different damage levels. In International workshop on performancebased seismic design (Vol. 28). Dept. of Civil Engineering, McMaster University, June 28-July 1.

Grünthal G (1998) European macroseismic scale 1998. European Seismological Commission (ESC). 
HAZUS (1999) Earthquake loss estimation Methodology HAZUS99 Service Release 2 (SR2) Technical Manual, Federal Emergency Management Agency (FEMA), Washington, DC, USA.

Ioannou I, Chandler R E, Rossetto T (2020) Empirical fragility curves: the effect of uncertainty in ground motion intensity. Soil Dynamics and Earthquake Engineering, 129, 105908. https://doi.org/10.1016/j.soildyn.2019.105908.

Khanmohammadi M, Eshraghi M, Behboodi S, Mobarake A A, Nafisifard M (2021) Dynamic Characteristics and Target Displacement of Damaged and Retrofitted Residential Buildings Using Ambient Vibration Tests Following Sarpol-e Zahab (Iran) Earthquake (MW 7.3). Journal of Earthquake Engineering, 1-28. https://doi.org/10.1080/13632469.2021.1911880.

Khanmohammadi M, Mazlaghani Z (2021) Piecewise incremental dynamic analysis (PIDA) based on the vector of intensity measures correlated with the structural responses. Soil Dynamics and Earthquake Engineering, 150, 106933. https://doi.org/10.1016/j.soildyn.2021.106933.

Kohrangi M, Bazzurro P, Vamvatsikos D (2021) Seismic risk and loss estimation for the building stock in Isfahan. Part I: exposure and vulnerability. Bulletin of Earthquake Engineering, 19(4), 1709-1737. https://doi.org/10.1007/s10518-020-01036-2.

Martins L, Silva V (2020) Development of a fragility and vulnerability model for global seismic risk analyses. Bulletin of Earthquake Engineering, 1-27. https://doi.org/10.1007/s10518-020-00885-1.

Miano A, Jalayer F, Forte G, Santo A (2020) Empirical fragility assessment using conditional GMPE-based ground shaking fields: Application to damage data for 2016 Amatrice Earthquake. Bulletin of Earthquake Engineering, 18(15), 6629-6659. https://doi.org/10.1007/s10518-020-00945-6.

Moosavi M, Ashayeri I, Haghshenas E, Biglari M, Kamalian M, Jalili J (2019) Preliminary Seismic Site Classification Map of Sarpol-e Zahab. Journal of Seismology and Earthquake Engineering, 20(4), 25-32.

Okada S, Takai N (2000) Classifications of structural types and damage patterns of buildings for earthquake field investigation. In Proceedings of the 12th world conference on earthquake engineering, Auckland, New Zealand (Vol. $30)$.

Omidvar B, Gatmiri B, Derakhshan S (2012) Experimental vulnerability curves for the residential buildings of Iran. Natural Hazards, 60(2), 345-365. https://doi.org/10.1007/s11069-011-0019-y.

ONBR (2013a) National building regulations, part 10: Design and construction of steel buildings, Office of National Building Regulations, Tehran, Iran.

ONBR (2013b) National building regulations, part 9: Design and construction of reinforced concrete buildings, Office of National Building Regulations, Tehran, Iran.

Otani S, Sozen M A (1972) Behaviour of multi-story reinforced concrete frames during earthquakes. Structural Research Series 392. Civil Engineering Studies, University of Illinois, Urbana, Ill.

Park J, Bazzurro P, Baker J W (2007) Modeling spatial correlation of ground motion intensity measures for regional seismic hazard and portfolio loss estimation. Applications of statistics and probability in civil engineering, 1-8.

Park Y J, Ang A H S (1985) Mechanistic seismic damage model for reinforced concrete. Journal of structural engineering, 111(4), 722-739. https://doi.org/10.1061/(ASCE)0733-9445(1985)111:4(722).

Rossetto T (2004) Vulnerability curves for the seismic assessment of reinforced concrete building populations.

Rossetto T, Elnashai A (2003) Derivation of vulnerability functions for European-type RC structures based on observational data. Engineering structures, 25(10), 1241-1263. https://doi.org/10.1016/S0141-0296(03)00060-9.

Rossetto T, Ioannou I, Grant D N, Maqsood T (2014) Guidelines for the empirical vulnerability assessment. 
Sadeghi M, Ghafory-Ashtiany M, Pakdel-Lahiji N (2015) Developing seismic vulnerability curves for typical Iranian buildings. Proceedings of the Institution of Mechanical Engineers, Part O: Journal of Risk and Reliability, 229(6), 627-640. https://doi.org/10.1177/1748006X15596085.

Sinha R, Shiradhonkar S R (2012) Seismic damage index for classification of structural damage-closing the loop. In Proceedings of the 15th World Conference On Earthquake Engineering, Libosa, Portugal.

Sozen M A (1981) Review of earthquake response of reinforced concrete buildings with a view to drift control. Stateof-the-art in Earthquake Engineering, 383-418.

Sozen M (1997) Drift-driven design for earthquake resistance of reinforced concrete. In EERC-CUREe Symposium in Honor of Vitelmo Bertero, Report UCB/EERC-97/05, EERC, University of California, Berkeley.

Tafti M F, Hosseini K A, Mansouri B (2020) Generation of new fragility curves for common types of buildings in Iran. Bulletin of Earthquake Engineering, 18(7), 3079-3099. https://doi.org/10.1007/s10518-020-00811-5.

Tavakoli, B, Favakoli A (1993) Estimating the vulnerability and loss functions of residential buildings. Natural Hazards, 7(2), 155-171. https://doi.org/10.1007/BF00680428.

United Nations Institute for Training and Research, Satellite image and analysis (2017) Maps and Data.

Yepes-Estrada C, Silva V, Rossetto T, D'Ayala D, Ioannou I, Meslem A, Crowley H (2016) The global earthquake model physical vulnerability database. Earthquake $\quad$ Spectra, 32(4), 2567-2585. https://doi.org/10.1193/011816EQS015DP.

Zafarani H, Jafarian Y, Eskandarinejad A, Lashgari A, Soghrat M R, Sharafi H, Afraz-e Haji-Saraei M (2020) Seismic hazard analysis and local site effect of the 2017 M w 7.3 Sarpol-e Zahab, Iran, earthquake. Natural Hazards, 103, 1783-1805. https://doi.org/10.1007/s11069-020-04054-0.

\section{Data Availability Statement}

Some of all data, models, and code that support the findings of this study are available from the corresponding author upon reasonable request.

\section{Funding}

This research did not receive any specific grant from funding agencies.

\section{Conflicts of interest/Competing interests}

The authors declare that they have no known competing financial interests or personal relationships that could have appeared to influence the work reported in this paper.

\section{Code availability}

Some or all, models or code that support the findings of this study are available from the corresponding author upon reasonable request.

\section{Acknowledgments}

This research did not receive any specific grant from funding agencies. 